\title{
Competencia en el mercado de banda ancha móvil en España*
}

\author{
Joan Calzada \\ Universitat de Barcelona \\ Fernando Martínez Santos \\ Universitat de Barcelona y Competition and Markets Authority, Reino Unido
}

\section{Resumen}

En los últimos años el servicio de banda ancha móvil ha tenido una fuerte expansión en España, hasta alcanzar una penetración de más del 70 por 100 de la población a principios de 2014. Este crecimiento puede explicarse por las prestaciones que ofrecen las tecnologías de tercera y cuarta generación en los terminales móviles actuales, y por las continuas reducciones de precios del servicio. A pesar de ello, los precios en España son todavía más altos que la media europea. Este artículo explica el proceso de innovación tecnológica que ha permitido el surgimiento de la banda ancha móvil, y su lanzamiento en España. Se examinan las nuevas estrategias comerciales que utilizan los operadores, como el empaquetamiento de servicios y los planes convergentes que incluyen servicios fijos y móviles. Nuestro análisis destaca que la presencia de los operadores móviles virtuales y el empaquetamiento han favorecido la competencia y la disminución de precios. También mostramos cómo la convergencia tecnológica entre los servicios fijos y móviles promueve la restructuración y concentración del mercado.

Palabras clave: telecomunicaciones, banda ancha móvil, España, competencia, regulación.

Clasificación JEL: L51, L86, L96.

\begin{abstract}
In the last few years, the mobile broadband service has experienced a significant expansion in Spain, reaching a penetration of over 70 per cent of the population at the beginning of 2014. This growth can be explained by the benefits that offer the third and the fourth generation of mobile technology, and by the continuous price reductions. In spite of this, prices in Spain are still higher than the European average. This paper explains the process of technological innovation that has allowed the emergence of mobile broadband, and its launch in Spain. New commercial strategies used by mobile operators, such as bundling and plans that include fixed and mobile services are examined. Our analysis shows that the presence of mobile virtual network operators and bundling have been effective in promoting competition and reducing prices. We also analyze how technological convergence between fixed and mobile services promotes restructuring and market concentration.
\end{abstract}

Keywords: telecommunications, mobile broadband, Spain, competition, regulation.

JEL classification: L51, L86, L96.

* Agradecemos a los editores, evaluadores anónimos, Daniel Ollé, Jesús Pascualena y Carlos Pérez Maestro todos sus numerosos comentarios y sugerencias a nuestro artículo. Este trabajo se ha beneficiado del apoyo financiero del Ministerio de Educación (ECO2012-33392) y de la Generalitat de Catalunya (SGR2014-325). 


\section{Introducción}

Los servicios de telecomunicaciones y de la sociedad de la información son uno de los principales motores de desarrollo económico y de cohesión social. La evidencia empírica muestra que el acceso a la banda ancha tiene un impacto positivo en factores macroeconómicos como el PIB, el empleo y la productividad ${ }^{1}$.

En 2010, la Comisión Europea (CE) lanzó la Agenda Digital Europea 2020 con el objetivo de crear un mercado único digital europeo. La Agenda Digital estableció varios objetivos a corto y medio plazo. El más inmediato era conseguir que todos los ciudadanos de la UE tuviesen la posibilidad de acceder a Internet en el año 2013. Este objetivo se cumplió meses antes de finalizar 2013 con una cobertura superior al 95 por 100 y al 99 por 100 para la banda ancha fija y móvil, respectivamente, que se completó hasta llegar al 100 por 100 con el acceso a Internet a través del satélite para llegar a las zonas remotas. En España, la cobertura de la banda ancha fija es de más del 95 por 100 de los hogares, y la de la banda ancha móvil del 98 por 100 del territorio.

Otro objetivo de la Agenda Digital es conseguir que en 2020 toda la población de la UE pueda acceder al servicio de Internet con velocidades superiores a $30 \mathrm{Mbps}$, y que al menos la mitad de los hogares puedan navegar a una velocidad superior a 100 Mbps. Por este motivo, la CE y las Autoridades Nacionales de Regulación (ANRs) promueven la inversión en redes de nueva generación, redes fijas de fibra y redes móviles de cuarta generación (4G).

El esfuerzo por impulsar la banda ancha se ha producido en un contexto de fuerte crisis económica y de aumento de la competencia, que han reducido de forma significativa los ingresos de los operadores. En la UE, estas reducciones se han producido sobre todo en los servicios de voz fija y móvil, que son los que tradicionalmente han tenido un mayor peso para los operadores, mientras que los ingresos provenientes de la banda ancha fija y especialmente de banda ancha móvil han tenido tasas de crecimiento positivas. En España, los ingresos totales de los servicios de telecomunicaciones no han dejado de reducirse desde 2008 (Gráfico 1). En particular, en 2013 se produjo una importante reducción de los ingresos provenientes del tráfico de voz móvil y fija, con caídas del 20,1 por 100 y 13,3 por 100 respectivamente. Mientras, los ingresos provenientes de banda ancha fija se redujeron un 2,2 por 100 y los de la banda ancha móvil aumentaron un 19,7 por 100 en 2013.

Los buenos resultados de la banda ancha móvil se deben a la fuerte expansión que está experimentando este servicio en España. Entre enero de 2013 y de 2014 la penetración pasó del 58 al 73 por 100, haciendo que España se sitúe como el octavo

\footnotetext{
${ }^{1}$ CRANDAL, L. et al. (2007) encuentran una causalidad positiva y significativa entre la penetración de banda ancha y la creación de empleo en EEUU. CZERNICH et al. (2011) estiman que un aumento del 10 por 100 en la penetración de banda ancha tiene un impacto en el crecimiento del PIB per capita de entre el 0,9 y el 1,5 por 100 .
} 


\section{GRÁFICO 1}

\section{TASAS DE CRECIMIENTO (PORCENTAJE) DE LOS INGRESOS EN TELECOMUNICACIONES EN ESPAÑA}

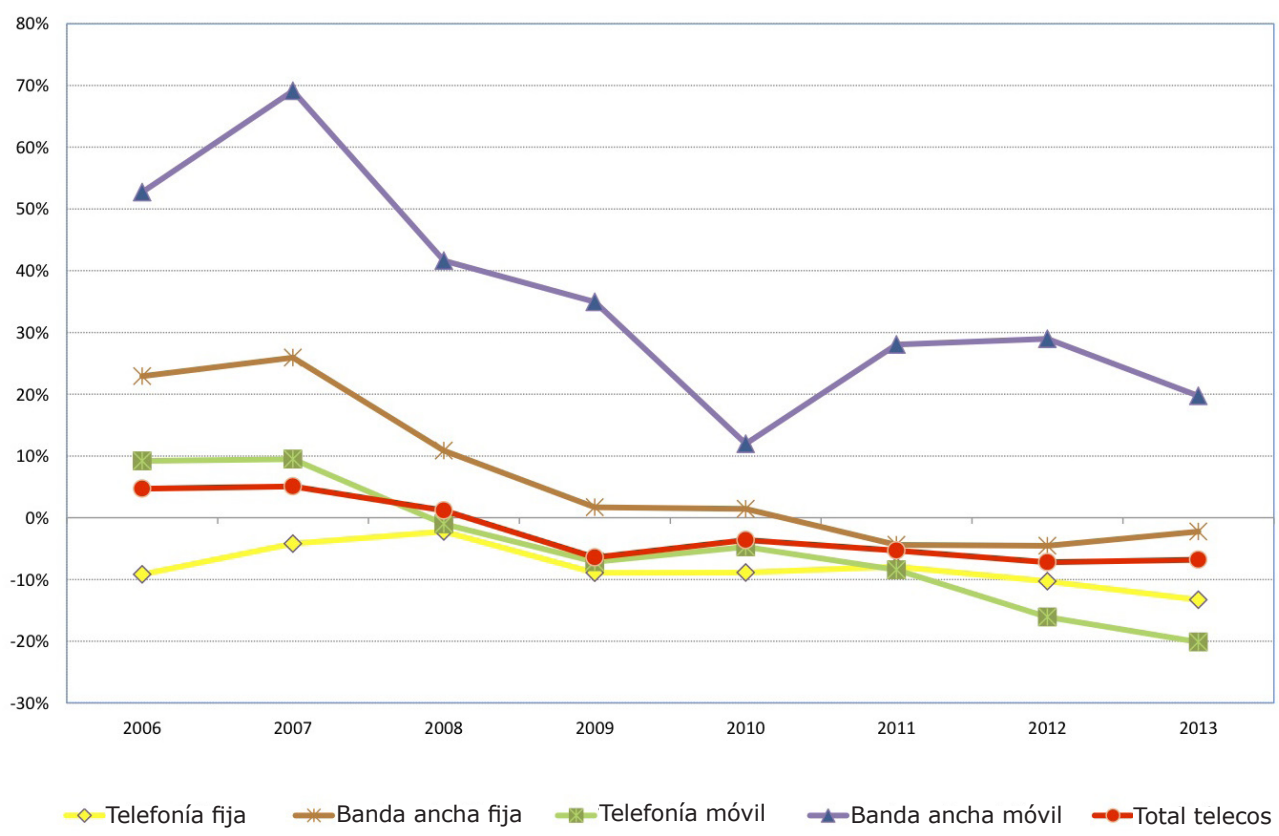

FUENTE: CNMC, informes anuales.

país de la UE-28 en la contratación del servicio. En cambio, el acceso a banda ancha fija fue del 26 por 100 en 2014, situando a España como el décimo país con una menor penetración en la UE-28 y por debajo del 30 por 100 de la media europea.

El lanzamiento de la banda ancha móvil y las aplicaciones de llamadas y mensajería están cambiando los hábitos de comunicación de la población, afectando a servicios fijos y móviles. Por otro lado, la difusión de las ofertas convergentes que empaquetan los servicios de voz y banda ancha fija y móvil provoca que los consumidores cada vez estén menos condicionados por los precios individuales de los servicios a la hora de comunicarse y que utilicen con más frecuencia los dispositivos móviles para acceder a Internet ${ }^{2}$.

Curiosamente, en España la rápida difusión de la banda ancha móvil se ha producido a pesar de existir un uso relativamente bajo de Internet. Según Eurostat ${ }^{3}$,

2 Varios trabajos han analizado los determinantes de la sustitución entre telefonía fija y móvil, llegando a conclusiones ambiguas. Ver una revision en VOGELSANG (2010) y GRZYBOWSKI (2012).

${ }^{3}$ Ver Eurostat, Community Survey on ICT Usage in Households and by individuals (2013). La CE (2013) señala que en la UE-27 el 27 por 100 de individuos usan frecuentemente sus smartphones para acceder a Internet y el 36 por 100 lo hacen a través de ordenadores portátiles o tabletas. Según este estudio la edad, la falta de habilidades y los precios son los principales motivos de no usar banda ancha móvil. 
a principios de 2013 el porcentaje de personas entre 16 y 74 años que accedieron a Internet al menos una vez al mes fue del 66 por 100 en España, un porcentaje considerablemente inferior al de otros países europeos como Francia (78 por 100), Alemania (80 por 100) y el Reino Unido (87 por 100). Además, un 24 por 100 de la población española nunca ha utilizado Internet. Por otro lado, en España sólo el 32 por 100 de la población compró productos o servicios por Internet en los 12 meses anteriores a ser entrevistados, una cifra muy por detrás de Francia (59 por 100), Alemania (68 por 100) y el Reino Unido (77 por 100). Ante estos resultados, nos podríamos preguntar cuáles son las causas del menor uso de Internet en España respecto a otros países de la UE y si la difusión de la banda ancha móvil puede ayudar a cambiar esta situación.

Este artículo se desarrolla de la siguiente manera. La sección 2 describe el proceso de cambio tecnológico que ha permitido la aparición de los nuevos estándares de banda ancha móvil. También explica la adopción de la tecnología 4G en España. La sección 3 examina la evolución de la penetración de la banda ancha móvil en España y compara los resultados con los del resto de países de la UE. Por otro lado, analiza cómo está cambiando la estructura del mercado. Finalmente, la sección 4 explica la aparición de nuevas prácticas comerciales en el mercado, en especial el empaquetamiento de servicios y las ofertas convergentes. También se analiza en detalle las ofertas comerciales de los operadores españoles en $2014^{4}$.

\section{El desarrollo tecnológico de la banda ancha móvil}

El avance tecnológico y la competencia han sido los dos factores más importantes para la difusión de la telefonía móvil y en la actualidad también lo están siendo para la expansión de la banda ancha móvil. A continuación analizamos el proceso de innovación tecnológica que ha permitido desarrollar estos servicios y las dificultades que se han producido en España para el despliegue del 4G.

\subsection{El nacimiento de la banda ancha móvil}

Los servicios móviles de transmisión de datos se han ido desarrollando progresivamente a través de diferentes estándares tecnológicos. La primera red comercial de telefonía móvil de primera generación (1G) se lanzó en Japón en $1979^{5}$, utilizando la tecnología analógica. El servicio se extendió rápidamente por el mundo

\footnotetext{
${ }^{4}$ Muy pocos artículos han estudiado los precios de la telefonía móvil. GRZYBOWSKI (2005 y 2008) y SUNG y KWON (2011) muestran el efecto de las regulaciones, los costes y la concentración del mercado en los precios. CALZADA y MARTÍNEZ SANTOS (2014) analizan los precios de la banda ancha fija en la UE.

${ }^{5}$ Según GRUBER y VALLETTI (2003), la telefonía móvil fue desarrollada en 1973 por Martin Cooper en Motorola y se empezó a comercializar por NTT DoCoMO en Tokio en 1979.
} 
a través de siete estándares que eran incompatibles entre sí. En Estados Unidos se implantó únicamente el estándar Analog Mobile Phone System, lo cual facilitó la difusión del servicio al reducir el coste de los equipos y facilitar el roaming nacional. En Europa, en cambio, la coexistencia de diversos sistemas nacionales incompatibles llevó a la fragmentación del mercado. El servicio y los terminales eran caros y el número de usuarios se limitó a unos pocos millones. En aquellos años los móviles sólo ofrecían el servicio de voz.

La situación cambió con la introducción de la tecnología de segunda generación (2G) en la segunda mitad de los 90. En 1982, la European Conference of Postal and Telecommunications Administrations mostró la urgencia de desarrollar un sistema europeo de telefonía móvil para evitar que la banda de 900 Mhz se acabase ocupando por sistemas nacionales incompatibles. Posteriormente, se decidió que en lugar de armonizar los sistemas nacionales se crearía conjuntamente una nueva tecnología. De este modo, el Groupe Spécial Mobile, formado por operadores europeos, diseñó un sistema europeo de telefonía móvil digital (Hillebrand, 2013). En 1987, los países y empresas involucrados en el estándar definieron las especificaciones técnicas básicas que debía tomar el 2G. El estándar adoptado se llamó Global System for Mobile Communications (GSM) y para formalizar el acuerdo los operadores de 14 países, entre ellos Telefónica, firmaron el GSM Memorandum of Understanding. Los firmantes se comprometieron a adoptar el GSM en sus países en 1991, y a asegurar la interoperabilidad de sus infraestructuras. En 1989, el GSM se transfirió al European Telecommunications Standards Institute (ETSI) y este estándar pasó a considerarse como obligatorio a nivel europeo.

El GSM se lanzó en Finlandia en 1991 y se extendió rápidamente por todo el mundo. En España, se concedieron licencias de GSM-900 a Movistar (Telefónica) y Airtel (posteriormente Vodafone) en 1995, y de GSM-1800 a Movistar, Airtel y Amena (posteriormente Orange) en 1998 (Calzada y Estruch, 2011).

Mientras tanto, en otros países como Estados Unidos, Australia, China o la India la elección del estándar quedó en manos de los propios operadores. En Estados Unidos se introdujo una versión del GSM, pero poco después se adoptaron otros estándares incompatibles, dificultando el roaming nacional (Gandal et al., 2003). A nivel mundial se desplegaron cuatro estándares de $2 \mathrm{G}$, aunque prácticamente el 80 por 100 de la población mundial acabó utilizando el GSM y más del 15 por 100 el estándar de Estados Unidos IS-95 (Interim Standard 95) ${ }^{6}$. La literatura económica ha señalado que la fragmentación del mercado en diferentes estándares y la obligación de pagar por recibir las llamadas (receiving party pays) son factores que retrasaron la expansión del móvil en Estados Unidos (Gruber y Verboven, 2001; Koski y Kretschmer, 2004).

\footnotetext{
${ }^{6}$ El GSM y el IS-95 se diferencian por su sistema de acceso. El GSM utiliza el TDMA (Time Division Multiple Access), que divide la frecuencia en slots y asigna uno de ellos a cada usuario. Por el contrario, el IS95 utiliza la tecnología CDMA (Code Division Multiple Access), que permite que todos los usuarios compartan el canal de frecuencia, pero las señales llevan un código para distinguir a cada uno de los usuarios.
} 
Algunas de las principales aportaciones del $2 \mathrm{G}$ fueron que sus redes tenían un coste de despliegue menor y que podían soportar un uso más intenso del servicio. Esto facilitó la concesión de varias licencias en cada país y la aparición de cierta competencia ${ }^{7}$. No obstante, el 2G tenía poca capacidad para la transmisión de datos, de modo que sólo ofrecía servicios como el envío de mensajes SMS o el contestador automático.

En los años siguientes numerosos grupos de trabajo fueron mejorando el estándar. El GPRS (General Packet Radio Service) es una evolución del GSM que permitió enviar paquetes de información realizando una actualización simple de las redes existentes. Este sistema 2.5G utiliza la tecnología IP (Internet Protocol) para acceder a los proveedores de contenido de Internet. Por otro lado, los consumidores pueden estar continuamente conectados a Internet y simultáneamente realizar llamadas. Otras tecnologías 2.5G fueron el Enhanced Data Rates for Global Evolution (EDGE) y el CDMA2000. Todas ellas permiten velocidades de entre los $40 \mathrm{kbps}$ y los $384 \mathrm{kbps}$, todavía insuficientes para soportar la banda ancha móvil.

A mediados de los años noventa, el objetivo de impulsar la transmisión de datos a alta velocidad llevó a la Unión Internacional de las Telecomunicaciones (UIT) a proponer un estándar global de tecnología de tercera generación (3G) con unos requisitos más exigentes. Se optó por el IMT-2000 (International Mobile Telecommunications 2000), que se basaba en el estándar CDMA2000 desarrollado por Qualcomm. Algunas características destacadas del IMT-2000 eran permitir el roaming global a través de un único terminal y aumentar más de 40 veces la velocidad de trasmisión respecto al $2 \mathrm{G}$.

En Europa, el IMT-2000 causó cierta incomodidad por el temor a que el GSM no evolucionase a tiempo para cumplir los requisitos exigidos. De este modo, el UMTS Forum buscó una alternativa europea para el 3G. A partir de las recomendaciones del UMTS Task Force, en 1997 se establecieron las especificaciones técnicas de un nuevo estándar. Un aspecto clave en este proceso fue que varios fabricantes pertenecientes al ETSI propusieron una variación del CDMA2000 llamada WCDMA (Wideband Code Division Multiple Access) que era incompatible con el sistema norte-americano ${ }^{8}$. Esto suponía que los terminales o las tarjetas que funcionaban con diferentes estándares no eran compatibles.

El apoyo del ETSI al WCDMA dejó claro que no se podía crear un único estándar para el IMT-2000. La UE, Estados Unidos y Japón querían que el 3G diese continuidad a sus estándares de $2 \mathrm{G}$. En este punto es importante mencionar que aunque la UIT se encarga de fijar las características de los estándares internacionales, posteriormente varios consorcios compuestos por empresas e instituciones definen las normas que

${ }^{7}$ En 1996, la CE aprobó la Directiva 96/2/CE que liberalizó el mercado y estableció como fecha límite para la concesión de nuevas licencias de GSM-1800 el 1 de enero de 1998 (BEKKERS, 2001).

${ }^{8}$ Según CABRAL y SALANT (2013), Estados Unidos logró que la UE revocara la decisión del ETSI de requerir a las ANRs que usaran el GSM, ya que esto violaba los tratados de política de competencia entre Estados Unidos y la UE. No obstante, los reguladores europeos realizaron una asignación del espectro radioeléctrico que impide el despliegue del CDMA2000. 
deben satisfacer sus operadores para cumplir con los estándares. En 1997, teniendo en cuenta los intereses existentes, la UIT acabó aprobando cinco sistemas de la familia de estándares IMT-2000. En la UE, todos los países acabaron adoptando el WCDMA, conocido también como UMTS (Universal Mobile Telecommunications System).

En 1998, los participantes en el GSM y en el IS-95 crearon dos proyectos globales que debían permitir desarrollar los estándares $3 \mathrm{G}$ a partir de los requisitos establecidos por el IMT-2000. El 3GPP (Third Generation Partnership Project), es la asociación que asumió la elaboración del UMTS, y que se encarga del mantenimiento de los estándares GSM, EDGE, WCDMA y HSPA (High Speed Packet Access), así como de desarrollar el nuevo estándar LTE (Long Term Evolution). Por otro lado, el 3GPP2 (Third Generation Partnership Project 2) es la asociación responsable de desarrollar el CDMA2000, el sucesor del IS-95. A partir de las especificaciones marcadas por la UIT, el UMTS y el CDMA2000 han ido evolucionando en paralelo.

El UMTS ofrece una calidad de voz muy similar a la ofrecida por la telefonía fija y permite a los consumidores utilizar aplicaciones multimedia y otros servicios que requieren un mayor ancho de banda, como las videoconferencias o el streaming. Por otro lado, ha permitido sacar al mercado ofertas exclusivas de 3G para acceder a Internet a través de tabletas y portátiles.

El estándar de $3 \mathrm{G}$ que ha tenido más éxito a nivel mundial es el UMTS, que ha llegado a ser utilizado por más del 70 por 100 de los suscriptores. Sin embargo, inicialmente la difusión del UMTS sufrió retrasos importantes (Gruber, 2007). Por un lado, en el momento en el que se concedieron las licencias no estaban disponibles ni los terminales ni muchas especificaciones técnicas necesarias para instalar las nuevas redes. Posiblemente, los avances en el 3G en Japón y Estados Unidos llevaron a la UE a lanzar su estándar cuando la tecnología no estaba a punto. Por otro, la concesión de las licencias de UMTS coincidió con la llamada crisis de las puntocom, que apareció en 2001 al desvanecerse las expectativas que los mercados financieros habían puesto en las telecomunicaciones, y en especial en Internet. Esta situación, unida a las grandes cantidades de dinero que los operadores pagaron por sus licencias en las subastas frenó la inversión en las nuevas redes. Los operadores preferían actualizar sus redes amortizadas antes que invertir en las nuevas ${ }^{9}$.

En España, el 13 de mayo de 2000 el Gobierno adjudicó cuatro licencias de UMTS, convirtiéndose así en el segundo país europeo en hacerlo después de Finlandia. Se concedió una licencia a cada uno de los operadores de GSM existentes y una cuarta licencia para Xfera (posteriormente Yoigo). No obstante, los retrasos en el lanzamiento de esta tecnología hicieron que la Comisión del Mercado de las Telecomunicaciones (CMT) recomendase impulsar temporalmente el sistema GPRS. El objetivo era crear demanda para las nuevas aplicaciones de telefonía móvil. Así, las primeras tarjetas duales UMTS/GPRS se pusieron a la venta por Vodafone en febrero de 2004 (alternaban entre los dos sistemas según la cobertura disponible)

\footnotetext{
9 Ver PRAT y VALLETTI (2003) para un análisis de la concesión de licencias 3G en la UE.
} 
y sólo podían usarse en ordenadores porque los teléfonos UMTS todavía tardaron meses en llegar.

Los nuevos terminales $3 \mathrm{G}$ ofrecían mayores posibilidades de uso, tipos de aplicaciones y de visualización de contenido. Pero las nuevas prestaciones también aumentaron considerablemente el tráfico de datos. Para atender a la nueva demanda, el 3GPP ha seguido mejorando el UMTS mediante actualizaciones como el 3.5G, el 3.75G, y el 3.9G. En particular, se han introducido estándares como el HSPA+, que compite en prestaciones con estándares de 4G como el LTE-Advanced. Sin embargo, la elevada latencia (tiempo de respuesta) del $3 \mathrm{G}$ y la demanda de mayores velocidades de transmisión, sobre todo tras la popularización de los smartphones y las tabletas, ha hecho necesario introducir un nuevo estándar.

El paso del 3G al 4G se puso en marcha en 2008, cuando la UIT presentó un conjunto de requisitos denominados IMT-Advanced que deben garantizar la puesta en marcha de la banda ancha móvil ${ }^{10}$. En la UE, el estándar $4 \mathrm{G}$ desarrollado por el 3GPP es el LTE-Advanced. La primera red comercial LTE se lanzó a finales de 2009, aunque las especificaciones definitivas del IMT-Advanced se anunciaron en $2012^{11}$.

El LTE ofrece velocidades de hasta $150 \mathrm{Mbps}$ en descarga y de hasta $50 \mathrm{Mbps}$ en subida de datos, una velocidad muy superior a la que ofrecen actualmente los operadores, y similar a la velocidad del ADSL. Estas prestaciones permiten hacer video-conferencias, compartir y descargar archivos como fotos, aplicaciones y contenidos audiovisuales de alta definición. También reduce considerablemente la latencia respecto al $3 \mathrm{G}$, lo cual es esencial para aplicaciones que requieran respuestas en tiempo real, como los juegos en red.

\subsection{Salida falsa de la banda ancha móvil en España}

Atendiendo a los objetivos de la EU-2020 Strategy en 2010 la CE reservó la banda de 790-862 MHz para el despliegue de la tecnología 4G. Esta banda de frecuencias es el llamado «dividendo digital», que debía liberarse en toda Europa con el paso de la televisión analógica a la digital («apagón analógico»). El motivo de reasignar la banda de los $800 \mathrm{MHz}$ a los operadores de móvil es que el uso de estas frecuencias mejora la calidad de la banda ancha móvil en movimiento, aumenta la cobertura en grandes edificios y permite cubrir una mayor parte del territorio a un coste menor ${ }^{12}$.

\footnotetext{
${ }^{10}$ Algunos requisitos para los estándares $4 \mathrm{G}$ son: 1) Estar basado en una red conmutada IP; 2) Ser interoperable con los estándares de $2 \mathrm{G}$ y 3G; 3) Ofrecer $100 \mathrm{Mbit} / \mathrm{s}$ en transmisión de datos para clientes móviles y $1 \mathrm{Gbit} / \mathrm{s}$ en usuarios en reposo; 4) Facilitar la asignación dinámica y el intercambio de recursos de red entre usuarios; 5) Permitir el uso variable de ancho de banda, desde 5 a $20 \mathrm{MHz}$.

${ }^{11}$ En 2010 la UIT declaró que los estándares candidatos para el 4G, como el LTE, podrían empezar a comercializarse como estándares 4G. No obstante, técnicamente el LTE es un estándar de transición.

${ }^{12}$ Aunque todo el espectro puede utilizarse para cualquier tecnología móvil, la propagación de las ondas electromagnéticas es mejor en frecuencias bajas y en el interior de los edificios. En cambio, las frecuencias altas de la banda de 2,6 GHz tienen más capacidad y son más adecuadas para poblaciones con una alta concentración de usuarios.
} 
En algunos países como Alemania, Holanda, Portugal y Suecia los operadores de móvil empezaron a utilizar la banda de $800 \mathrm{MHz}$ en 2012. En España, en 2009 el Ministerio de Industria presentó un Real Decreto para asignar a la telefonía móvil las frecuencias liberadas entre 790 y $862 \mathrm{MHz}$, y $190 \mathrm{MHz}$ que estaban libres en la banda de 2,6 GHz.

En verano de 2011 se adjudicaron a los operadores de móvil las frecuencias en la banda de $800,900,1800 \mathrm{MHz}$ y 2,6 GHz. El 90 por 100 de las frecuencias se concedieron por subasta y el resto por concurso. Telefónica, Vodafone y Orange obtuvieron a través de la subasta el máximo de frecuencias permitidas en 800 y 900 MHz. No obstante quedó libre un bloque en las «mejores» frecuencias de 800 y 900 Mhz. Para algunos, el hecho de que Yoigo no pujara por ellas fue la constatación de que el operador había renunciado a convertirse en un operador nacional con capacidad para competir con los otros operadores móviles con red (OMRs). Otros potenciales candidatos a estas frecuencias eran Jazztel y ONO, los únicos entrantes en la telefonía fija con una implantación nacional. Sin embargo, estos operadores tampoco pujaron por esta banda, posiblemente debido al alto precio de reserva establecido en la subasta y por el coste de despliegue de la infraestructura. Por otro lado, a través del concurso Orange y Yoigo accedieron a frecuencias en la banda de $900 \mathrm{MHz}$ y $1800 \mathrm{Mhz}$, respectivamente ${ }^{13}$.

Aunque estas adjudicaciones se realizaron en 2011, se espera que los operadores puedan empezar a utilizar las frecuencias de $800 \mathrm{MHz}$ a principios de 2015 debido a los retrasos en la reconfiguración del mercado de la TDT. En diciembre de 2012 el Tribunal Supremo declaró nulo el acuerdo del Consejo de Ministros de 16 de julio de 2010 por el que se adjudicaron canales de televisión a Atresmedia, Mediaset, Veo TV y Net TV. La razón era que los canales se adjudicaron sin realizar el preceptivo concurso público, tal como establecía la nueva Ley General de Comunicación Audiovisual. La sentencia obligó al Gobierno a reestructurar el mercado de la $\mathrm{TDT}^{14}$.

En mayo de 2014 se decretó el cierre de los nueve canales de televisión anulados por el Tribunal Supremo y en septiembre se lanzó un nuevo Plan Técnico de la TDT. El Plan establece que un 30 por 100 de las frecuencias que utilizan las televisiones privadas nacionales se destinarán a incrementar la oferta actual de canales. Por otro lado, un 20 por 100 de las frecuencias radioeléctricas se reasignarán a los servicios de telefonía móvil $4 \mathrm{G}$.

Otra explicación del retraso en la reasignación de frecuencias es que requiere resintonizar de nuevo las antenas de televisión de los edificios. El anterior Gobierno del PSOE estimó que esta operación tendría un coste de unos 800 millones de euros,

${ }^{13}$ Entre Movistar, Vodafone y Orange pagaron más de 1.647 millones de euros por las frecuencias, y los operadores de cable 24 millones adicionales. Otros operadores que también invirtieron en espectro, aunque mucho menos, fueron Jazztel, Euskaltel, R, TeleCable y Telecom CLM.

${ }^{14}$ En julio de 2013 la CE autorizó a España a retrasar la asignación de la frecuencia de $800 \mathrm{MHz}$ hasta 2014. La Comisión también aceptó un aplazamiento para Chipre, Lituania, Hungría, Malta, Austria, Polonia, Rumanía y Finlandia, y lo denegó para Eslovaquia y Eslovenia. 


\section{GRÁFICO 2 \\ COBERTURA DE LAS TECNOLOGÍAS 3G Y 4G EN ESPAÑA Y EN LA UE-27}

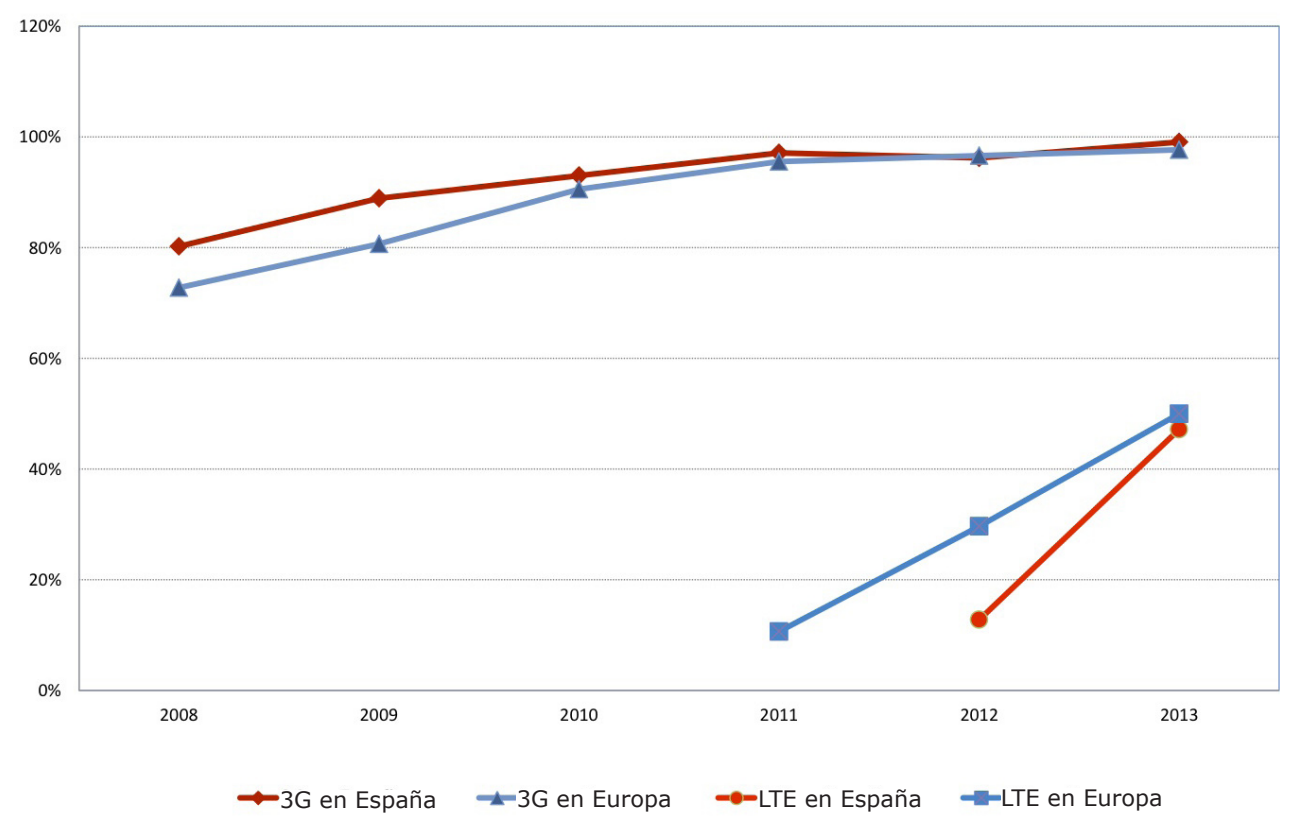

FUENTE: Comisión Europea.

y consideró que se debía asumir por parte del Estado por qué era consecuencia de una mala planificación en el lanzamiento de la TDT. Posteriormente, el Plan de la TDT de 2014 modificó el proyecto y rebajó el coste de la reantenización a 286 millones de euros.

Curiosamente, mientras España y otros países están liberando la banda de 800 $\mathrm{MHz}$, la CE ha empezado a valorar la posibilidad de liberar la banda de los $700 \mathrm{MHz}$ (Ultra High Frequency Spectrum) para destinarla a las comunicaciones móviles y cumplir los objetivos de la Agenda Digital. La creación de este segundo dividendo digital puede chocar de nuevo con los intereses de los operadores de TDT, que deberían desplazarse a la banda de 470-690 MHz. Esta medida tendría un mayor impacto en España que en otros países europeos, ya que la cuota de mercado de la TDT es muy alta en relación a la de otras plataformas audiovisuales como el cable o el satélite.

\subsection{Primeras ofertas comerciales de $4 G$}

Los retrasos en la reasignación de las frecuencias no han impedido que algunos operadores españoles hayan empezado a ofertar servicios de $4 \mathrm{G}$ a través de la banda de $1800 \mathrm{MHz}$ y de 2,6 GHz. En mayo de 2013 Vodafone activó el servicio de 4G 
en siete ciudades (Barcelona, Bilbao, Madrid, Málaga, Palma de Mallorca, Sevilla y Valencia) e inició una intensa campaña comercial para promocionar el servicio. En julio, Yoigo y Orange respondieron con una estrategia parecida, ofreciendo el servicio en las grandes ciudades españolas y ampliando progresivamente su cobertura. Cuando se lanzó el servicio, algunos operadores crearon ofertas de 4G con unos precios más altos, pero posteriormente eliminaron los pagos adicionales.

Movistar inicialmente decidió esperar a tener las frecuencias de $800 \mathrm{MHz}$ para lanzar el 4G, pero cuando vio que sus rivales empezaban a ofrecer el servicio buscó un acuerdo de compartición de redes con Yoigo. Telefónica y Yoigo comercializan ofertas convergentes de fibra y $4 \mathrm{G}$, aprovechando las redes de banda ancha fija y móvil de última generación de ambos operadores. En paralelo, Movistar está desplegando su propia red ${ }^{15}$. Según la CNMC (2014d), en 2013 del total de 5,866 estaciones base de $4 \mathrm{G}$ instaladas, Yoigo tenía el 33,2 por 100, Orange el 27,1 por 100, Vodafone el 20,3 por 100 y Movistar el 19,3 por 100 .

En las siguientes secciones analizamos con más detalle el servicio de banda ancha móvil en España. Primero examinamos la estructura del mercado, y posteriormente evaluaremos la evolución de la competencia y de los precios.

\section{Estructura del mercado de banda ancha móvil en España}

En 2012, después de varios años de lento crecimiento, la penetración de la telefonía móvil ${ }^{16}$ retrocedió ligeramente y ya no volvió a aumentar hasta julio de 2014, para situarse en el 109,2 por 100 (50,7 millones de líneas), un nivel parecido al de 2007 (Gráfico 3). La reducción de la penetración se debe sobre todo al segmento residencial, muy aquejado por la crisis y el desempleo. Muchos consumidores particulares han unificado sus comunicaciones bajo un mismo número y prescinden de las segundas líneas. Por otro lado, las empresas y otras instituciones han reducido el número de terminales de sus empleados. Es importante destacar que este fenómeno se ha producido en paralelo a las bajadas de precios y al descenso en el tráfico de voz, lo cual ha reducido significativamente los ingresos de los operadores. Si en 2007 los ingresos finales del móvil fueron de 14.103 millones de euros, en 2013 la cifra se había reducido hasta los 7.576 millones, una magnitud cercana a la conseguida en 2012

La comparación con los países de la UE-28 muestra que España tiene uno de los niveles de penetración del móvil más bajos de Europa, lo cual seguramente se pueda

15 El acuerdo contempla que Movistar ofrezca servicios 4G sobre la red de Yoigo y que este pueda vender un paquete combinado con sus servicios móviles y los servicios fijos de Movistar (voz y banda ancha, tanto ADSL como fibra). Además, Yoigo sigue utilizando las redes de transporte de Telefónica para las tecnologías 2G y 3G. En noviembre de 2013 la CNMC abrió un expediente sancionador a Telefónica y Yoigo por los acuerdos alcanzados, y ahora analiza sus posibles efectos anticompetitivos.

${ }^{16}$ La penetración del servicio móvil se define como el número de tarjetas SIM activas por cada 100 personas. 
GRÁFICO 3

PENETRACIÓN DE LOS SERVICIOS DE TELEFONÍA MÓVIL EN ESPAÑA

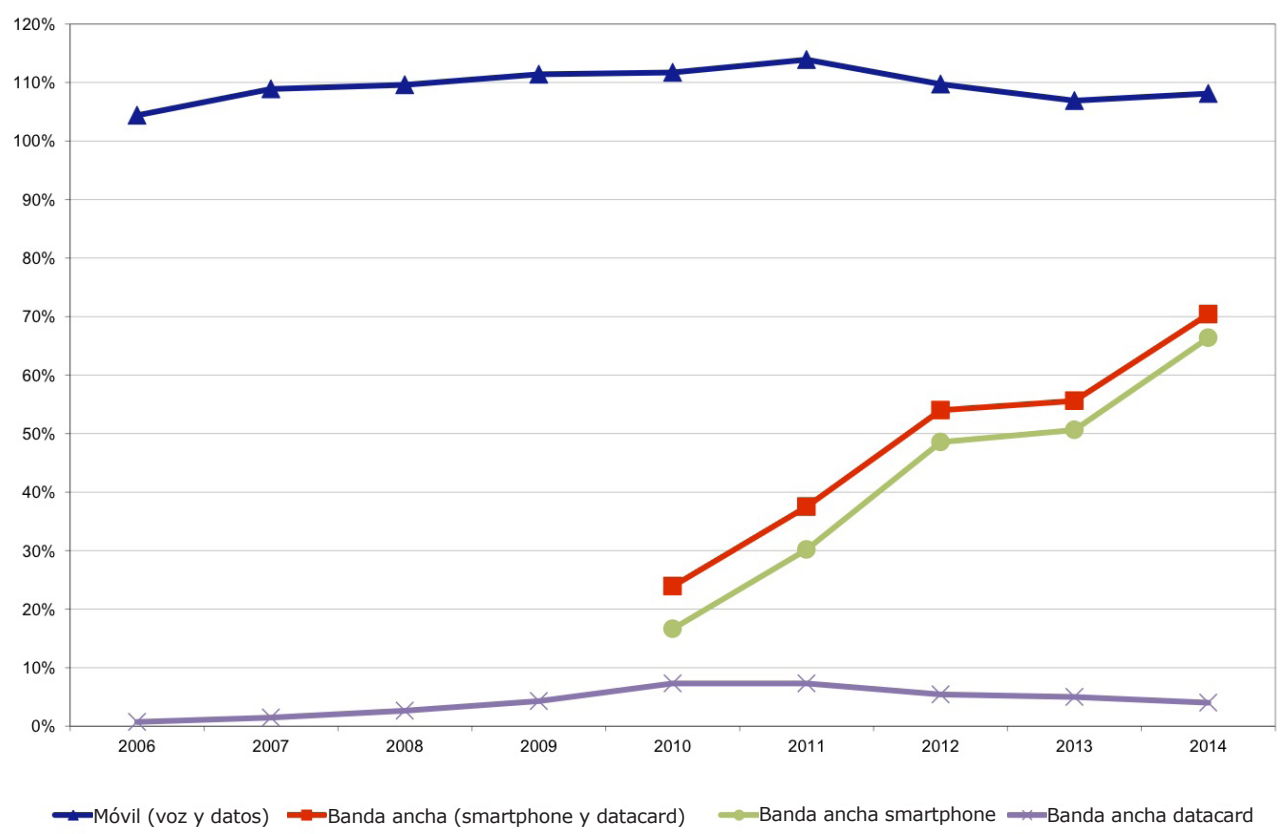

FUENTE: CNMC, informes anuales.

explicar por los altos precios que tradicionalmente han existido en el país ${ }^{17}$ (Gráfico 4). Por otro lado, también se debe destacar que en España el 70 por 100 de los contratos son de postpago, un porcentaje más alto que en muchos otros países europeos.

La banda ancha móvil sigue una evolución diferente al resto de servicios de telecomunicaciones. La penetración de las líneas vinculadas a la banda ancha en smartphones lleva varios años creciendo a un fuerte ritmo y llegó al 70,4 por 100 de la población (30,9 millones de líneas) en el primer trimestre de 2014. Este crecimiento puede explicarse por la buena acogida que han tenido las aplicaciones móviles entre la población y por las continuas reducciones de precios que se han ido produciendo en los últimos años. Los ingresos provenientes de la banda ancha móvil están creciendo a muy buen ritmo pero no compensan los malos resultados del resto de servicios de comunicaciones (ver Gráfico 1). También es importante destacar que España tiene una penetración de la banda ancha móvil superior a la media europea de la UE-28, pero ha perdido puestos en el ranking de implantación del servicio. La penetración en España fue del 73 por 100 en enero de 2014, y la media de la UE-28 del 63 por 100. Los países que lideran la difusión del servicio son Finlandia, Suecia y Dinamarca, donde la penetración supera el 100 por 100 (Gráfico 4).

\footnotetext{
17 Ver los informes de la Comisión Europea (2012a, 2012b, 2013) y de la OCDE (2011, 2013).
} 


\section{GRÁFICO 4 \\ PENETRACIÓN DE BANDA ANCHA MÓVIL (ENERO 2014) Y DE TARJETAS SIM ACTIVAS EN EUROPA \\ (Octubre de 2013)}

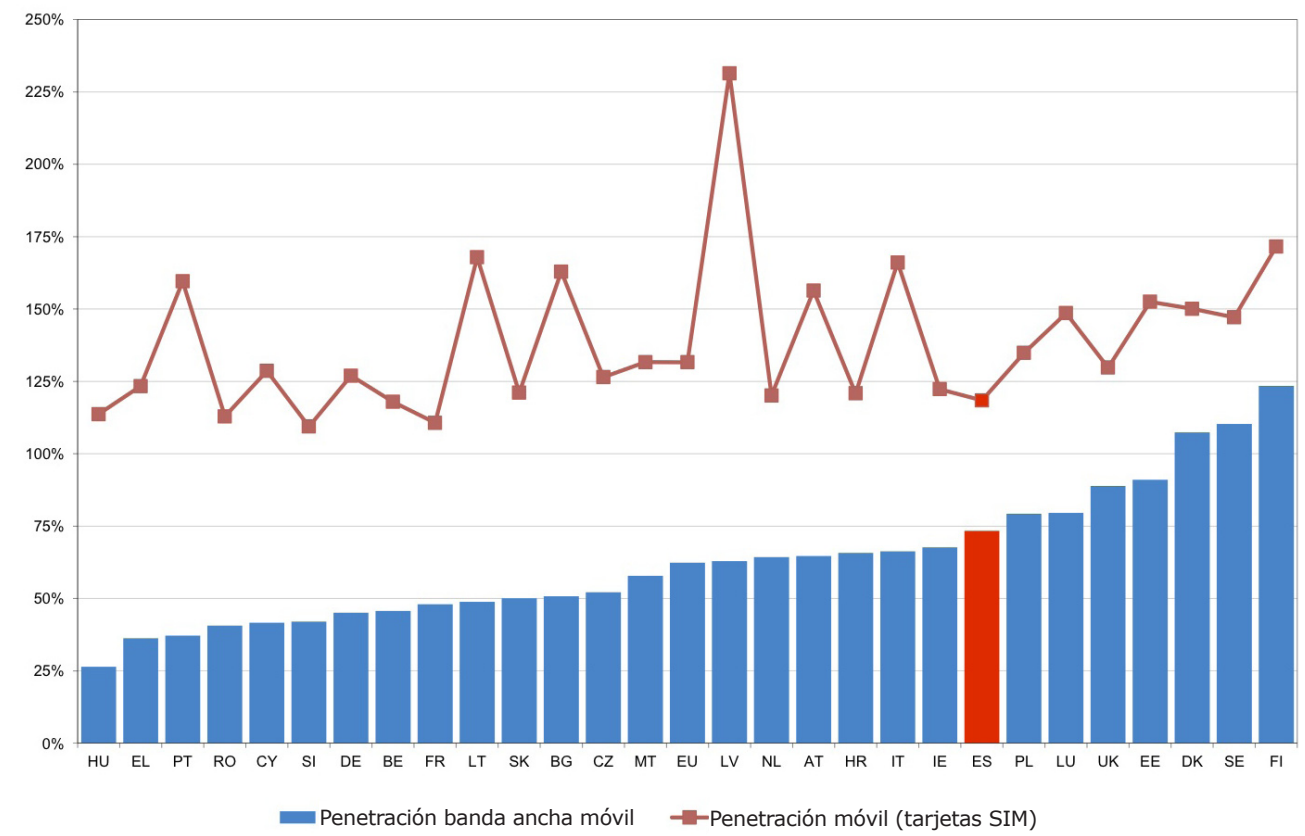

FUENTE: Comisión Europea.

Por otro lado, las conexiones a través de dispositivos móviles vinculadas exclusivamente al servicio de tráfico de datos (datacards) crecieron de forma importante hasta verano de 2011, cuando llegaron a las 3,6 millones de líneas, pero después se redujeron drásticamente hasta llegar a los 1,8 millones en julio de 2014 (Gráfico 3). Estos resultados sugieren que las datacards para módems USB han quedado obsoletas con la irrupción de los smartphones, las tabletas y los portátiles con tarjetas SIM integradas.

En los últimos años, la intensificación de la competencia provocada por la regulación, el aumento en el número de operadores y la convergencia tecnológica ha transformado la estructura del mercado del móvil. El número total de líneas de Movistar y Vodafone se ha reducido a un ritmo sostenido, y el de Orange ha aumentado ligeramente (Gráfico 5). Por otro lado, Yoigo y los OMVs han aumentado su cuota de mercado de forma significativa desde su aparición, y juntos sumaron el 23 por 100 de las líneas en julio de 2014. En abril de 2013, por primera vez en la historia, los cuatro OMRs perdieron abonados y los OMVs ganaron líneas en conjunto. Como consecuencia, el mercado español tiene una estructura similar al de otros países 


\section{GRÁFICO 5}

CUOTAS DE MERCADO POR OPERADOR DE LÍNEAS DE TELEFONÍA MÓVIL EN ESPAÑA

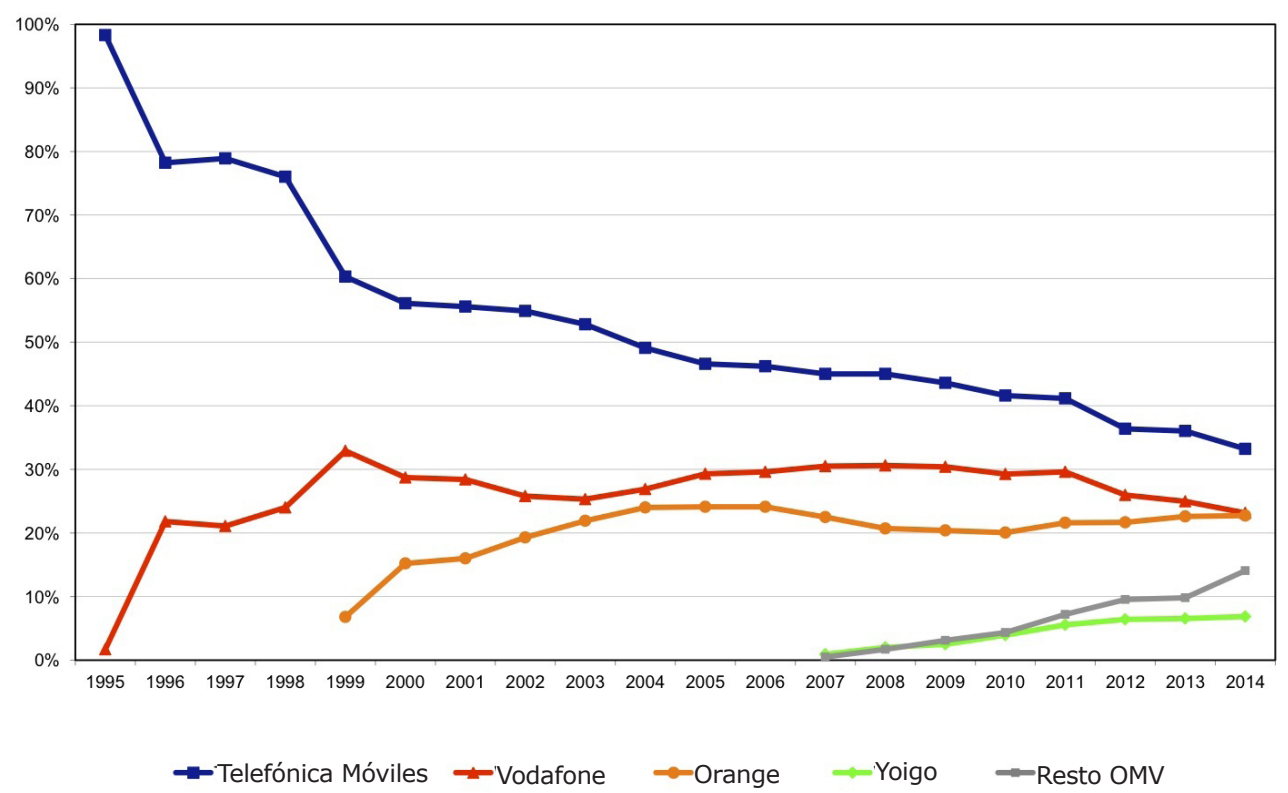

FUENTE: CNMC, informes anuales.

europeos de referencia. De acuerdo con Ofcom (2014), en 2013 Movistar tenía una cuota de mercado del 38 por 100 de las conexiones, mientras que el operador líder en Francia tenía una cuota del 36 por 100, en Italia del 33 por 100, en Alemania del 32 por 100 y en el Reino Unido del 31 por 100.

Las cuotas de mercado para el servicio de banda ancha móvil son algo diferentes que para el conjunto de los servicios móviles. Según la CNMC, en el primer trimestre de 2014, Movistar tenía una cuota de mercado de líneas de móvil del 33,2 por 100, y de líneas vinculadas a la banda ancha móvil del 31,8 por 100. En el caso de Vodafone, las cuotas respectivas eran del 23,1 por 100 y 24,3 por 100, en Orange del 22,7 por 100 y 22,1 por 100 , en Yoigo del 6,8 por 100 y 9,3 por 100, y para los OMVs del 14 por 100 y 12,3 por 100. Por tanto, las cuotas de mercado de la banda ancha móvil son parecidas a las totales, excepto en el caso de Yoigo que tiene una mayor cuota de banda ancha. También es importante señalar que si tuviésemos en cuenta los ingresos obtenidos por los operadores o el tráfico que generan nos encontraríamos un mercado más concentrado, ya que Movistar y Vodafone tienen una mayor cuota de ingresos al tener más clientes de postpago que realizan un mayor consumo que los de prepago.

Finalmente, uno de los principales indicadores para evaluar el estado de la competencia es la portabilidad. Dado que la mayor parte de los consumidores ya tienen una línea fija y otra móvil, la forma que tienen los operadores de conseguir más clien- 
tes es arrebatándoselos a sus rivales, por ejemplo rebajando precios. En junio de 2012, la CMT aprobó una medida que acortó de cuatro a un solo día hábil el período necesario para hacer efectiva una solicitud de portabilidad de una línea de móvil. Esta modificación de la regulación ha provocado un aumento de la portabilidad. En 2013, por ejemplo, se portaron más de 160.000 números fijos y más de 560.000 números móviles cada mes. Los operadores que más han ganado con estos movimientos son los entrantes, Yoigo y los OMVs (Gráfico 6) ${ }^{18}$.

En un estudio con datos para un panel de hogares españoles, la CNMC muestra que en 2013 el porcentaje de individuos con telefonía móvil que cambiaron de operador fue del 17,2 por 100 , superior al 11,7 por 100 de 2012 , y al 14,4 por 100 de $2011^{19}$. El aumento se produjo tanto en telefonía de postpago, 20,7 por 100, como de prepago, 8,3 por 100 . En el primer caso, este resultado estaría vinculado a la contratación de ofertas convergentes. Según el estudio, el motivo más citado para cambiar de operador fue abaratar el gasto $(64,4$ por 100), cambiar de móvil aprovechando una promoción $(24,8$ por 100$)$, la insatisfacción con el servicio $(24,3$ por 100$)$, y la búsqueda de tarifas más simples (19 por 100), entre otros (CNMC, 2014c).

Los recientes acontecimientos en el mercado permiten vislumbrar una reconfiguración de la que todavía no se saben las consecuencias. Hasta hace poco existían cuatro OMRs que ofrecían servicios $3 \mathrm{G}$ con redes propias y que tenían la obligación de alquilar sus redes a los OMVs. Por otro lado, existían 24 OMVs (algunos participados mayoritariamente por un $\mathrm{OMR}^{20}$ ) que tenían acuerdos con los OMRs para ofrecer servicios 3G. La llegada de los OMVs a partir de 2007, la regulación de los precios de terminación, y la crisis económica, entre otros, han favorecido que todos estos operadores compitan en precios, aunque varios OMVs se han especializado en grupos concretos de consumidores. Entre los entrantes, Yoigo ha tenido un papel destacado, desarrollando una política comercial diferente a la de los OMRs. Por otro lado, ONO y Jazztel han entrado en el mercado del móvil actuando como OMVs para sus clientes de servicios fijos. De este modo, existen varios operadores que comercializan ofertas convergentes de fijo y móvil, lo cual ha dinamizado la competencia.

Sin embargo, cabe preguntarse si el reciente lanzamiento del 4G puede afectar el funcionamiento del mercado. Hasta ahora, el único OMV que ha negociado la utilización de las redes 4G es Pepephone. En febrero de 2014 este operador rompió su acuerdo mayorista con Vodafone a favor de Yoigo al no llegar a un acuerdo para usar su red 4G. Sin embargo, la alianza con Yoigo no se materializó debido a que éste no tenía el permiso de Movistar para realquilar su red. Finalmente, Pepephone llegó a un acuerdo con Movistar para ofrecer 4G a finales de 2014. En los próximos

\footnotetext{
${ }^{18}$ En enero de 2014, 674,720 usuarios cambiaron de compañía móvil, lo que supone un récord histórico, según destaca la CNMC en su nota mensual sobre el sector.

19 En telefonía fija el porcentaje de usuarios que utilizó la portabilidad fue en 2013 del 15,4 por 100, marcando un récord de 1,9 millones de líneas portadas.

${ }^{20}$ Por ejemplo, Movistar compró Tuenti en 2010, Orange relanzó la marca a Amena en 2012 y compró a Simyo en el mismo año, y Euskatel tienen un acuerdo comercial con RACC móvil desde 2009. En 2012, cerca del 60 por 100 de los ingresos de los OMVs provenían de ofertas especializadas en tarifas internacionales.
} 
meses será importante examinar que facilidades encuentran el resto de OMVs para llegar a pactos con los OMRs. La competencia en el mercado podría verse dañada si los acuerdos para utilizar las redes $4 \mathrm{G}$ se retrasan.

La llegada del 4G también ha coincidido con varias adquisiciones de operadores que tienen como objetivo crear operadores globales con capacidad para comercializar ofertas convergentes. En 2014, Vodafone compró a ONO y Orange lanzó una oferta pública de compra por Jazztel. Estas compras permitirán a estos operadores entrar rápidamente en el servicio de banda ancha fija. Es importante resaltar que buena parte de los buenos resultados de ONO y Jazztel en los últimos tiempos se debe a que han comercializado ofertas convergentes de telefonía fija y móvil actuando como OMVs en la parte móvil. Algo parecido ha ocurrido con compañías de cable regionales como R Cable o Euskaltel, que se han hecho con una buena cartera de clientes de móvil y han adquirido licencias $4 \mathrm{G}$ para sus demarcaciones. La convergencia tecnológica y la concentración del mercado están siendo especialmente intensas en España y será importante estar pendientes de sus efectos.

\section{GRÁFICO 6}

\section{EVOLUCIÓN MENSUAL DEL SALDO NETO DE LÍNEAS MÓVILES POR OPERADOR EN ESPAÑA}

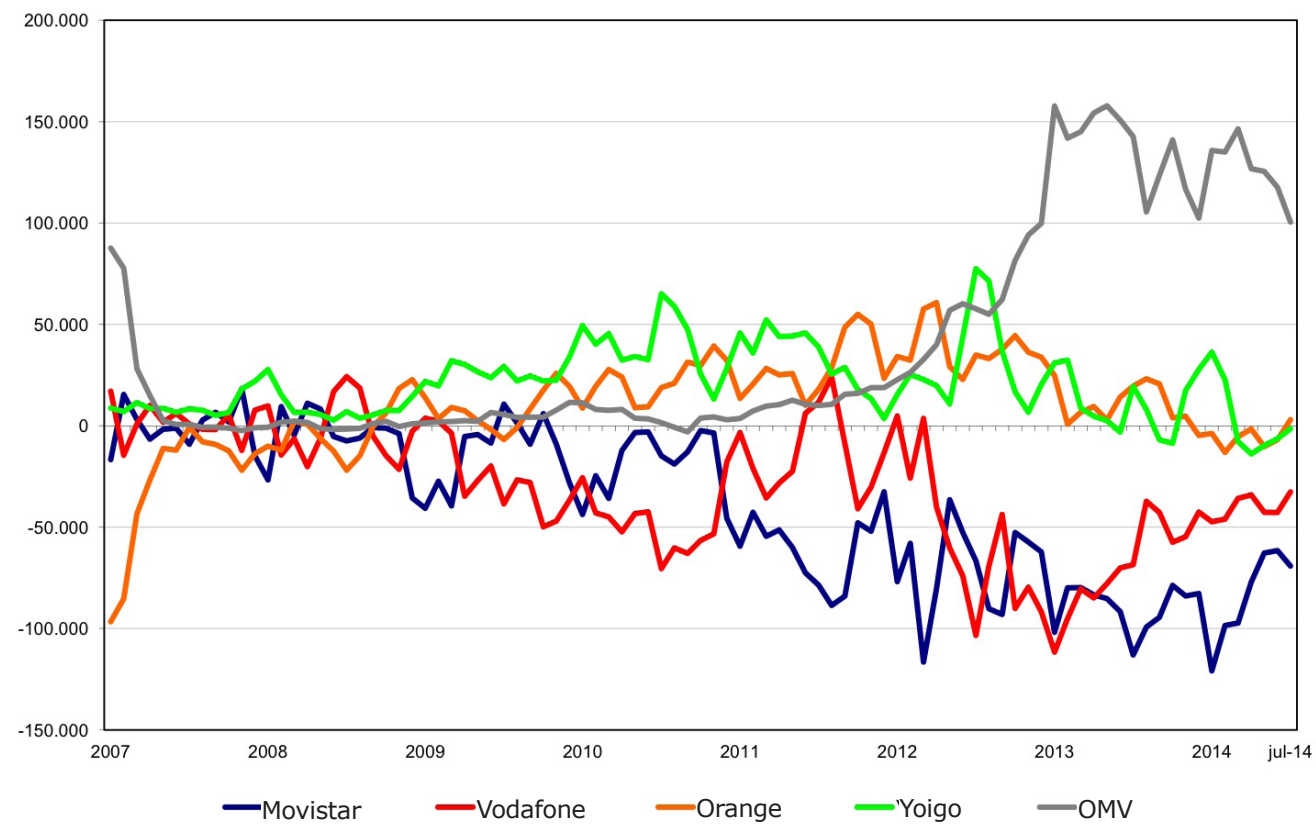

FUENTE: CNMC, informes mensuales. 
Otro aspecto relevante que puede afectar al mercado es la posibilidad de que los operadores lleguen a acuerdos de compartición de infraestructuras y de co-inversión en el despliegue de las redes LTE, como el alcanzado en 2014 por Yoigo y Movistar. Según la CMT (2013), tanto la CE como las ANRs son favorables a estos acuerdos cuando suponen compartir las infraestructuras pasivas (emplazamientos, antenas), como viene ocurriendo desde hace años. En cambio, cuando se trata de coordinar infraestructuras activas (redes de acceso radio, itinerancia o roaming nacional) se debe considerar su impacto en la reducción de costes y los efectos negativos en la competencia. La compartición activa implica que un operador pueda acoger en su red a clientes de otros operadores que no tienen frecuencias o que no han desplegado aun sus infraestructuras, o incluso que los operadores pongan en común sus redes para acceder a ellas indistintamente. El elemento crucial en este tema es si estos acuerdos pueden inducir a los operadores a alcanzar otros de carácter anticompetitivo.

\section{Competencia y estructura tarifaria}

El mercado de telefonía móvil español se caracterizó durante años por su falta de competencia, lo cual se evidencia al comparar los precios en España con los de otros países de la UE o de la OCDE. Una explicación de esta situación es que en los noventa se aplicó una regulación poco estricta con el objetivo de garantizar la rentabilidad de los operadores y fomentar la inversión. De hecho, en 1998 se abandonó la regulación de los precios minoristas de Movistar cuando únicamente existían dos operadores en el mercado. Las autoridades españolas esperaban que cuando el mercado madurase se intensificaría la competencia y que esto disciplinaría los precios. Cuando a mediados de 2000 se constató que esto no ocurría se introdujeron varias medidas correctoras, en muchas ocasiones impulsadas por las instituciones europeas.

Una regulación que ha demostrado ser efectiva para potenciar la competencia ha sido la reducción de los precios de terminación. La CMT ha ido bajando progresivamente los precios de terminación que pagan los operadores cuando inician una llamada que termina en la red de un rival (glide path). Siguiendo las recomendaciones de la $\mathrm{CE}$, los precios de terminación que cobran los cuatro OMRs se han reducido hasta llegar a los 1,09 céntimos de euro/minuto en julio de $2013^{21}$. Además, se ha pasado de unos precios de terminación asimétricos a fijar los mismos precios para todos los operadores. Esta medida ha bajado los precios de las llamadas off-net y ha disminuido la diferencia de precios entre las llamadas on-net y off-net $t^{22}$. Como consecuencia, el número de consumidores que tienen los operadores en su red es ahora un aspecto menos relevante a la hora de fijar los precios. Esto permite que

21 En 2012 la CMT llevó a cabo el análisis del mercado de terminación de llamadas en redes móviles individuales. Como resultado, concluyó que todos los OMRs y los OMVs completos (ONO, DigiMobil, Fon You, Euskatel, TeleCable, R, Lycamobile, Jazztel, Simyo) tienen poder significativo de mercado.

${ }^{22}$ Las llamadas on-net se originan y terminan en la red del operador, mientras que las llamadas off-net se inician en la red del operador y terminan en la red de un rival. 
los entrantes ofrezcan unos precios más atractivos y similares a los de las empresas establecidas (Calzada y Estruch, 2013). Por otro lado, la convergencia entre los precios on-net y off-net también puede haber influido en la aparición de las tarifas planas y semiplanas.

La otra medida que más ha favorecido la intensificación de la competencia es, sin duda, la llegada de los OMVs. La entrada de Xfera (posteriormente Yoigo) como cuarto operador en 2000 podría haber paliado la falta de competencia en el mercado español, pero entonces era demasiado tarde para que este operador instalara una red de GSM (aunque podría haber utilizado el roaming nacional) y todavía era pronto para que desplegase una red de UMTS (esta tecnología todavía no estaba bien desarrollada). Ni la «crisis de las puntocom» en 2001 ni la regulación de los OMVs ayudaron a que el operador saliera al mercado, perdiendo unos años muy valiosos para afianzar su posición. Finalmente, en 2006 la CMT obligó a los tres operadores móviles establecidos a alquilar sus redes a sus competidores. Esto favoreció la entrada de Yoigo, que llegó a un acuerdo con Movistar para usar su red allí donde no había desplegado la suya. En los años siguientes entraron en el mercado numerosos OMVs que introdujeron nuevas prácticas comerciales y estimularon la competencia en precios.

Finalmente, otro factor, en este caso ajeno al mercado, que permite entender la intensificación de la competencia es la crisis económica que padece el país desde el año 2008. La crisis ha llevado a las familias y empresas a optimizar su gasto y contratar las ofertas más económicas y ajustadas a sus necesidades.

\subsection{Nuevas prácticas comerciales: empaquetamiento y ofertas convergentes}

En los últimos años los operadores de telecomunicaciones han introducido nuevas estrategias comerciales para atraer usuarios y fidelizar a sus clientes. Una de estas es la venta de paquetes que incluyen los servicios tradicionales de voz y mensajería (SMS) junto con Internet. El empaquetamiento supone varias ventajas para los usuarios. Por un lado, los productos empaquetados suelen incluir descuentos. Por otro, los consumidores sólo necesitan acudir a un único número de atención al cliente, pueden controlar mejor sus facturas, y predecir su gasto total en servicios de telecomunicaciones ${ }^{23}$.

En 2013, la penetración de la telefonía móvil fue de 50,2 millones de líneas en España. De estas, 31,4 millones correspondían a líneas con acceso a Internet y 18,4 millones de líneas empaquetaban tráfico de datos con otros servicios, generalmente voz. Según la CNMC (2014d), entre 2012 y 2013 el número de personas que contrataron el servicio de Internet empaquetado aumentó en 10 millones el número de personas que compraron el servicio de Internet empaquetado aumentó en 10 millones.

${ }^{23}$ El empaquetamiento es un tipo de discriminación de precios que permite a los operadores segmentar a los consumidores y extraer una mayor renta de ellos. Por otro lado, también puede generar economías de alcance y otro tipo de ahorros. Ver ADAMS y YELLEN (1976), EVANS y SALINGER (2005), McAFEE et al. (1989) y NALEBUFF (2004). 
Una de las nuevas modalidades de contratación que ha tenido un mayor crecimiento son las ofertas convergentes, que combinan servicios de voz y banda ancha ofrecidas tanto por redes fijas como por móviles. En septiembre de 2012, Movistar lanzó la oferta convergente Movistar Fusión, que tuvo muy buena acogida por parte de los consumidores. De hecho, Movistar contrarrestó temporalmente la pérdida de clientes de ADSL y de móvil que estaba sufriendo ${ }^{24}$.

La estrategia de Movistar forzó la reacción de sus competidores y originó una guerra de precios. En noviembre de 2012, Vodafone y Orange trataron de replicar las ofertas de Movistar, aunque Vodafone no ofrecía la opción adicional de contratar el servicio de televisión. Una limitación de estos operadores es que sólo ofrecen estas ofertas en las zonas donde tienen acceso directo, es decir, donde no dependen enteramente de la red de Telefónica para ofrecer ADSL. A finales de 2013, Yoigo también lanzó una oferta convergente gracias a su acuerdo de compartición de redes con Movistar. Esto hace que los precios de Yoigo y Movistar sean muy parecidos, por la posibilidad de que los clientes de Yoigo contraten la parte fija de Movistar y cambien su tarifa móvil a una que sea compatible con Movistar Fusión. Por otro lado, ONO y Jazztel también ofrecen ofertas convergentes actuando como OMVs.

Las ofertas convergentes han tenido un gran éxito comercial. A finales de 2012 había 1,2 millones de conexiones de ofertas convergentes y a finales de 2013 la cifra se había quintuplicado. Existían 5,2 millones de ofertas de paquetes cuádruples, que agrupan los servicios de voz y banda ancha prestados desde red fija y móvil, y 700 mil ofertas de paquetes quíntuples, que incluyen además el servicio de televisión de pago.

En resumen, la dinámica de los últimos años es que los operadores más consolidados en el sector fijo han ganado presencia en el mundo móvil y los que tenían mayor número de clientes de móvil ganan (aunque en menor medida) clientes en el sector fijo. En 2013 Movistar, Vodafone y Orange tuvieron reducciones importantes de clientes en el móvil, que no pudieron compensar con sus ofertas convergentes. No obstante, estos operadores aumentaron su número de líneas de banda ancha fija, e incluso Orange consiguió ser líder en la portabilidad en ADSL. Por su parte, Jazztel y ONO son los operadores que más se beneficiaron con las ofertas convergentes, liderando la captura de clientes de móvil.

Según la CNMC (2014a), los potenciales ahorros que suponen las ofertas convergentes han producido un importante efecto arrastre. Mientras que en el tercer semestre de 2012 el 37,2 por 100 de los hogares con acceso fijo y móvil contrataron todas sus líneas con un único operador, a mediados de 2013 este porcentaje había aumentado hasta el 44,6 por 100. Sorprendentemente, el estudio de la CNMC muestra que el gasto de los hogares cuando contratan los servicios fijos y móviles con un único operador o con varios es parecido «a nivel agregado», aunque puede haber diferencias significativas entre hogares según sus patrones de gasto.

${ }^{24}$ Los competidores de Movistar denunciaron que esta oferta no era replicable, dado los precios mayoristas que Telefónica cobra por el uso de su red. Pero en junio de 2013 la CMT archivó las denuncias, poniendo de relieve el gran número de ofertas parecidas que se han lanzado desde 2012. 
El Gráfico 7 muestra que España es uno de los cuatro países europeos con una mayor penetración de productos empaquetados por habitante, detrás de Italia, Dinamarca y Eslovenia. Además, España es el segundo país con un mayor nivel de penetración de los paquetes con tres o más servicios, sólo por detrás de Eslovenia. Los datos de la $\mathrm{CE}$ muestran el rápido crecimiento del número de las líneas que tienen algún tipo de empaquetamiento. Si en 2012 la penetración de las líneas empaquetadas era del 71 por 100, en 2013 fue del 105 por 100. Más concretamente, los paquetes de más de tres servicios pasaron de una penetración del 40 por 100 en el 2012 a una del 63 por 100 en 2013; frente al 31 por 100 y 42 por 100 de los paquetes dobles.

Finalmente, otro tipo de prácticas comerciales que han surgido a partir de 2013 son la eliminación de los periodos de permanencia obligatorios en las ofertas de postpago y la decisión de algunas compañías como Movistar de comercializar terminales sin bloqueo de operador. También en 2013, algunos operadores trataron de eliminar las subvenciones de los terminales, aunque la presión competitiva provocó que más tarde las volvieran a ofrecer. Estos cambios y las reducciones de precios explican por qué en los últimos meses se ha llegado a cifras record de portabilidad.

\section{GRÁFICO 7 \\ PENETRACIÓN DEL EMPAQUETAMIENTO DE SERVICIOS EN LA UE-28, JULIO 2013}

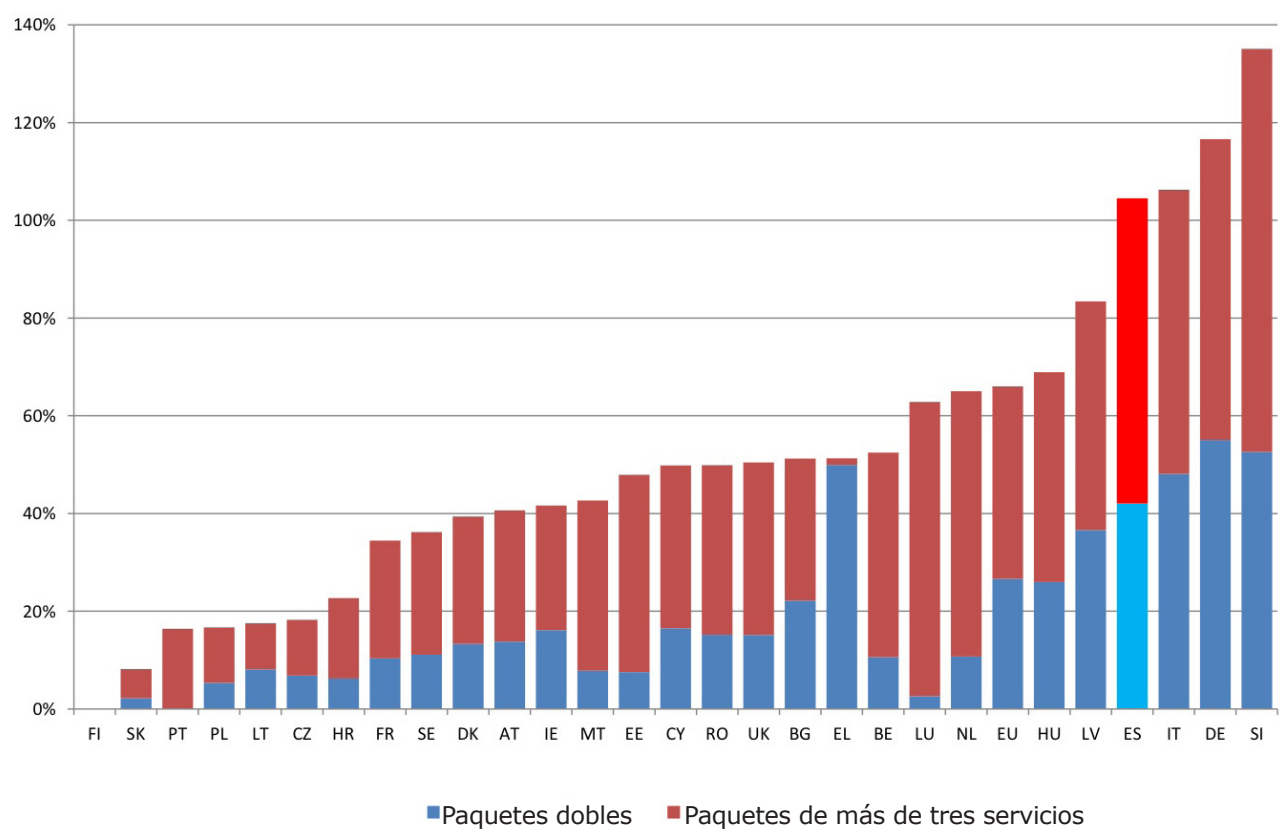

FUENTE: Comisión Europea. 


\subsection{Análisis de los precios}

La intensificación de la competencia ha tenido un impacto positivo en los precios del móvil, incluyendo los de la banda ancha móvil. El Gráfico 8 muestra que en España los ingresos medios por línea de móvil (ARPU, Average Revenue Per User) se han reducido a la mitad desde 2006 a 2014, pasando de 59 a 29 euros por línea y trimestre. Las reducciones empezaron a producirse en 2008 y se han intensificado en los últimos trimestres. También se puede ver que la bajada de ingresos es más importante en los contratos de postpago. Además, en 2013 el ingreso medio por minuto cayó un 27 por 100 para los clientes de contrato y un 20 por 100 para los de prepago $^{25}$. Según la CNMC (2014c), la reacción de Movistar y Vodafone ante la pérdida de clientes ha sido reducir sus precios, de modo que ofrecen planes tan económicos como los de sus rivales.

A pesar de lo anterior, para tener una visión más general de la competencia en España, es útil comparar los precios españoles con los de otros países europeos. La OCDE ha desarrollado una metodología para comparar los precios de la telefonía móvil. Se calculan cestas de 30, 100, 300 y 900 llamadas distribuidas en períodos pico y valle que realizaría un consumidor representativo, y que además incluyen el gasto en mensajes SMS. El Gráfico 9 muestra los precios para cestas de consumos intermedios de 100 y 300 llamadas en agosto de 2012. Para cestas de 100 llamadas, España tiene los precios más altos detrás de Italia y Hungría, y para cestas de 300 llamadas tiene los precios más altos detrás de Hungría, la República Checa y Portugal. Estos resultados sugieren que en España todavía existe margen para conseguir mayores reducciones de precios. En todo caso, para orientar la política regulatoria en el móvil parece imprescindible investigar con más detalle cuáles son los factores que explican las diferencias de precios entre España y el resto de países europeos.

En el caso de la banda ancha móvil, el Gráfico 10 muestra la evolución trimestral del ARPU para líneas de contrato y de prepago de banda ancha móvil entre el primer trimestre de 2012 y 2014. En este período se produjo una reducción del 24 por 100 en el ingreso medio total, lo cual refleja la intensidad de la competencia.

Finalmente, el Gráfico 11 vuelve a comparar los precios en España con los de otros países europeos. Con datos de la ITU se muestra el coste mínimo incurrido (en dólares ajustados por poder adquisitivo) por un consumidor al contratar una oferta de smartphone de $500 \mathrm{MB}$ de descarga en la UE-27, en su mayoría ofertas de postpago. Los resultados revelan que en 2013 España fue el sexto país con unos precios más altos en banda ancha móvil, detrás de Malta, Irlanda, República Checa, Bulgaria y Chipre. Estos datos sólo muestran una instantánea para un tipo de servicio de banda ancha móvil, pero dan una idea de la importancia de contrastar los datos de España con los de otros países europeos.

${ }^{25}$ Las reducciones de precios han impulsado el consumo. En 2013 el tráfico de minutos aumentó en un 34 por 100 y el de datos en un 115 por 100. Por el contrario, el tráfico de SMS apenas varió (CNMC, 2014c). 
GRÁFICO 8

EVOLUCIÓN DEL ARPU TRIMESTRAL EN LA TELEFONÍA MÓVIL EN ESPAÑA

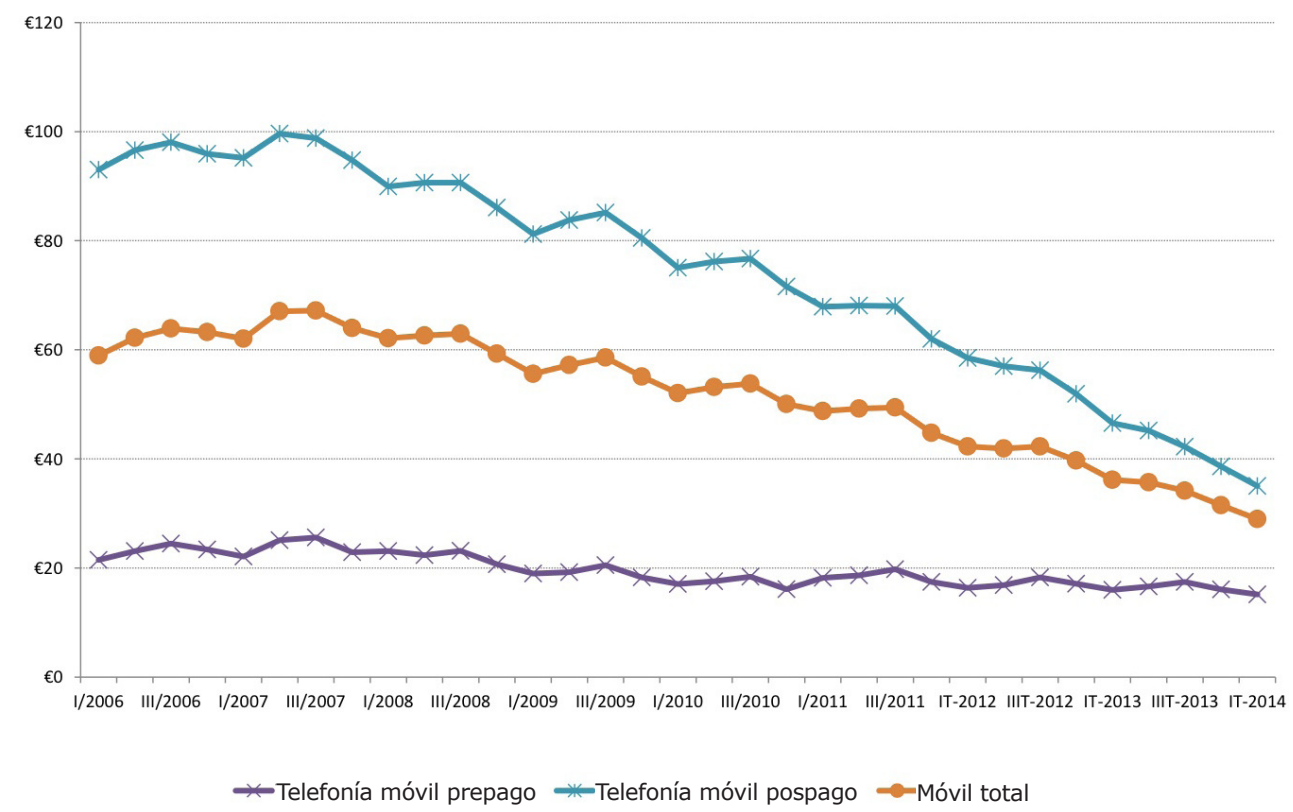

FUENTE: CNMC, datos trimestrales. 


\section{GRÁFICO 9}

PRECIOS DE LLAMADAS DE MÓVIL, AGOSTO 2012 (IVA INCLUIDO, \$ PPP)

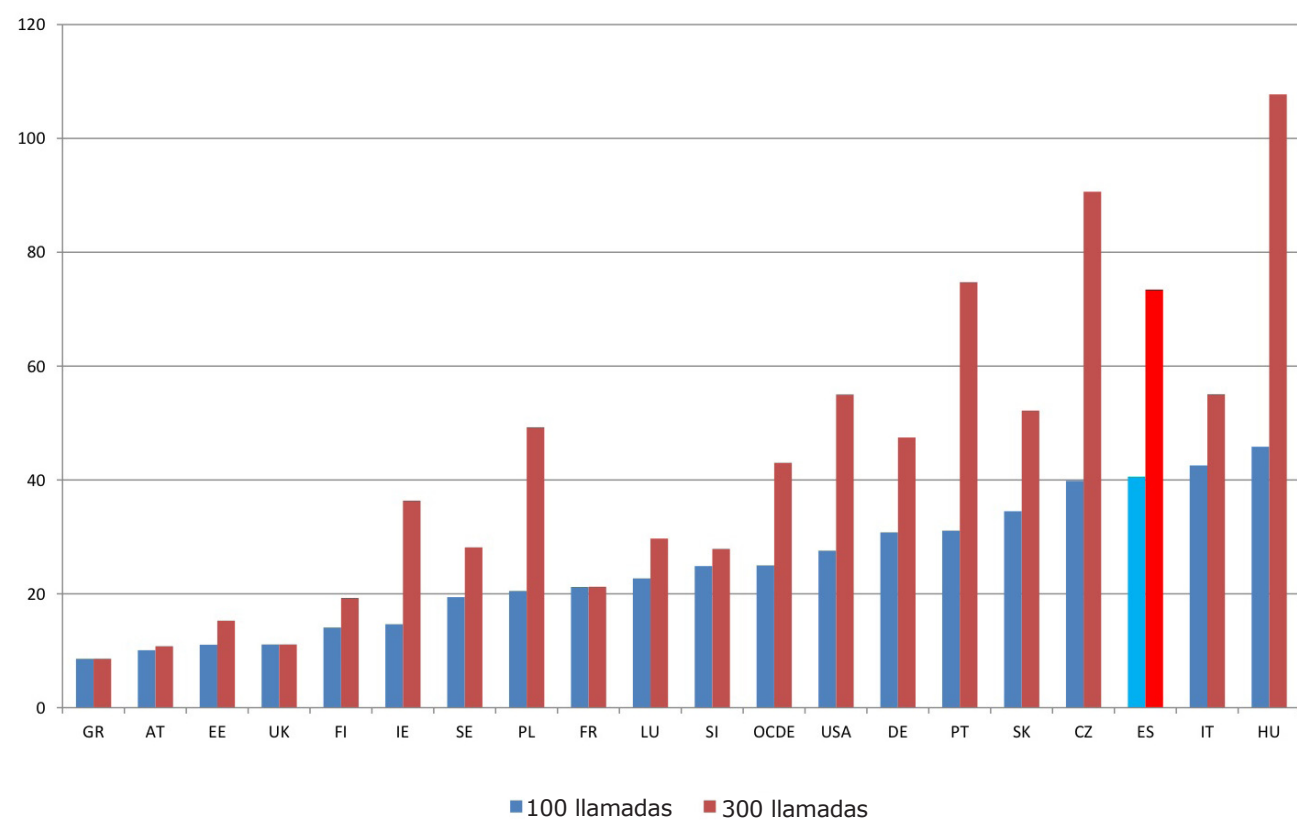

FUENTE: OCDE (2013). 


\section{GRÁFICO 10}

ARPU DE LÍNEAS DE BANDA ANCHA MÓVIL POR TRIMESTRE EN ESPAÑA

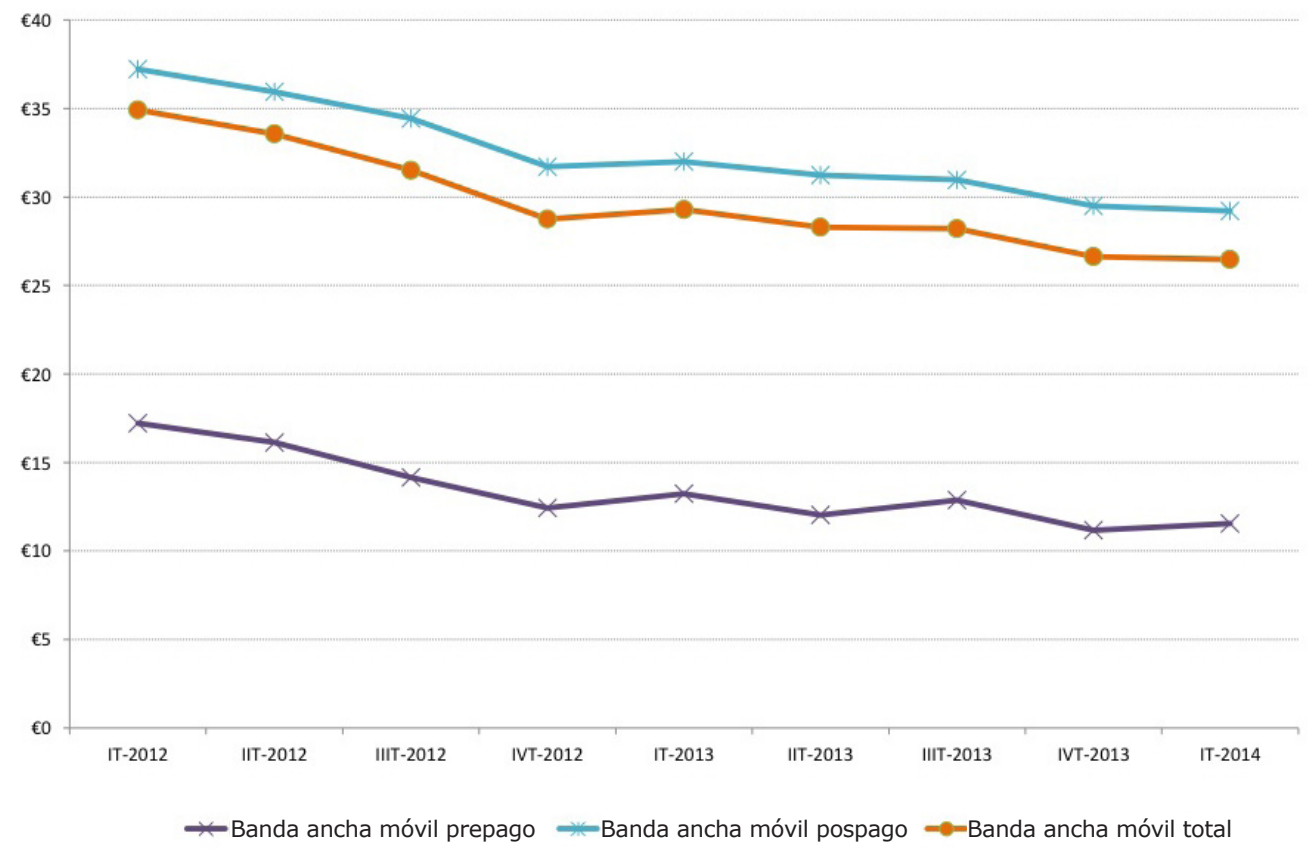

FUENTE: CNMC, datos trimestrales. 


\section{GRÁFICO 11 \\ PRECIOS MÍNIMOS (\$PPP) DE LA BANDA ANCHA MÓVIL (SMARTPHONE) EN LA UE-27, 2012}

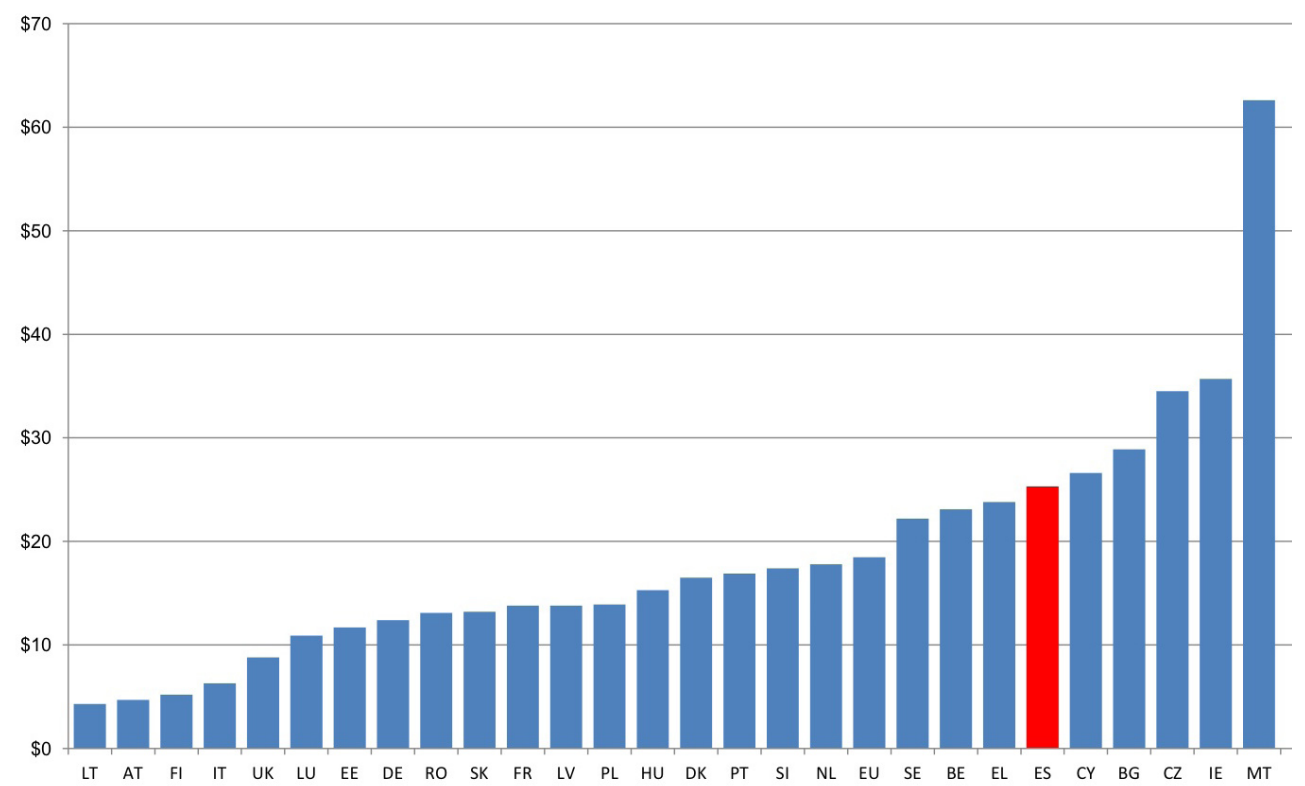

NOTA: Las ofertas de Alemania, Francia, Polonia, Reino Unido y República Checa son de prepago. FUENTE: UIT, Measuring the Information Society 2013

\subsection{Ofertas de banda ancha móvil españolas}

A continuación analizamos las características de las ofertas de banda ancha móvil para smartphones en el mercado residencial español. Nuestro estudio se basa en una muestra de 54 ofertas de banda ancha móvil, 35 de las cuales incluyen además un bono con minutos para llamadas. Los datos se han recogido de las páginas webs de los operadores en el tercer trimestre de 2014. Casi la mitad de las ofertas son de Movistar, Vodafone, Orange y Yoigo. El resto provienen de los OMVs con una mayor presencia en el mercado: Pepephone, Simyo, Tuenti, MásMóvil y HappyMóvil.

Las páginas web de los operadores clasifican las tarifas según si el pago del servicio se domicilia (postpago) o se descuenta del saldo en la tarjeta SIM (prepago). En los dos casos, las dos principales características de las ofertas son el volumen de descarga de datos y los minutos de llamadas incluidos. Tan sólo un reducido número de ofertas son exclusivamente para navegar por Internet con tabletas o portátiles a 
través de módems USB o MiFi (wifi móvil), lo cual reafirma la pérdida de interés por este tipo de servicio. Finalmente, las ofertas de los operadores pueden incluir la venta de una amplia gama de smartphones o tabletas subvencionados, que suelen estar sujetos a unos meses de permanencia y que en algunos casos están liberados. Los operadores también suelen discriminar en sus precios y subvenciones de terminales entre clientes antiguos y nuevos, y a su vez entre consumidores de prepago y de postpago.

Las ofertas de los OMRs y OMVs presentan distintas características tecnológicas y se comercializan de forma diferente. Los OMVs no tienen aún acceso a la tecnología 4G (Pepephone podrá empezar a comercializar 4G próximamente) y sus volúmenes de descarga no suelen superar un gigabyte. Los OMRs, en cambio, tienen diversas ofertas con límites de volumen de descarga por encima de dos gigabytes. Es interesante observar que Movistar publicita en su web las ofertas de su marca Tuenti, lo cual le permite competir directamente con los OMVs por consumidores que tienen un patrón de consumo medio y bajo. Cabe destacar que ninguna oferta ofrece un volumen de descarga ilimitado, posiblemente para evitar el arbitraje.

La mayoría de OMVs tienen ofertas que ofrecen volúmenes de descarga próximos a un gigabyte y que empaquetan datos con minutos de voz. También tienen planes para clientes de bajo consumo, por debajo de $500 \mathrm{MB}$. En cambio, los OMRs comercializan ofertas con mayores volúmenes de descarga para clientes que tienen un elevado uso de Internet (casi todas sus ofertas tienen volúmenes por encima de $500 \mathrm{MB}$ ). Por ejemplo, Orange y Vodafone ofrecen hasta cinco y seis gigabytes de descarga de datos respectivamente para banda ancha móvil en smartphone, frente a los dos gigabytes máximos de Simyo o 1,9 de Pepephone.

Algunos OMVs como MásMóvil y Simyo permiten a sus clientes configurar su oferta combinando una variedad amplia de bonos de datos y de voz. Otros como Tuenti se han orientado al público juvenil, y sus servicios empaquetados incluyen voz IP. Por otro lado, mientras que casi todas las ofertas de los OMRs incluyen una cantidad de datos para poder navegar por Internet (suelen tener una oferta de sólo voz en prepago), los OMVs tienen un mayor número de ofertas de sólo voz.

Finalmente, los OMVs analizados no ofrecen subsidios para la compra del terminal y los móviles que comercializan son de venta libre. Es posible que los OMVs hayan apostado por no subsidiar los terminales a cambio de ofrecer unas tarifas más económicas, pero no está claro que puedan mantener esta política si se reducen las diferencias de precios $^{26}$. También sería interesante examinar si los OMRs españoles que están implantados en varios países son capaces de ofrecer mejores subsidios para terminales gracias a su poder de negociación con los fabricantes de móviles.

${ }^{26}$ CMT (2013b) analiza la política de subvención de terminales en 2012, llegando a la conclusión de que los operadores que ofrecen subsidios para los terminales no tienen necesariamente precios más altos. 


\subsubsection{Precios de las ofertas de banda ancha móvil}

A continuación examinamos los precios mensuales de las ofertas de banda ancha móvil y de banda ancha móvil con minutos de voz comercializadas en España. Cabe señalar que las ofertas examinadas son heterogéneas en sus características técnicas (volumen de descarga y tecnología) y que los operadores utilizan diferentes estrategias comerciales como el empaquetamiento (bonos de minutos de voz y/o mensajes de texto), penalizaciones cuando el usuario consume todos los megabytes incluidos en la oferta (cobro por megabytes adicionales de datos, reducción de la velocidad), el subsidio de terminales, las promociones, etcétera. De todas estas características, sólo reflejamos el volumen de descarga (en gigabytes) y los minutos de llamadas de las ofertas.

Los Gráficos 12 y 13 muestran los precios de las ofertas según su volumen de descarga (en gigabytes) y los minutos de llamadas incluidos en la tarifa. Los dos gráficos diferencian las ofertas de los OMRs (azul) y de los OMVs (rojo). También distinguen las ofertas de sólo banda ancha (círculos) y los paquetes que incluyen banda ancha y minutos de voz (esferas). Los minutos de voz de las ofertas empaquetadas se reflejan en el tamaño de la esfera. Mientras que existen ofertas con minutos ilimitados de voz, no hay ningún plan que sea ilimitado en descarga de datos (el máximo volumen ofrecido es seis gigabytes).

\section{GRÁFICO 12}

PRECIOS DE LAS OFERTAS POSTPAGO DE BANDA ANCHA MÓVIL (Euros, IVA incluido, octubre 2014)

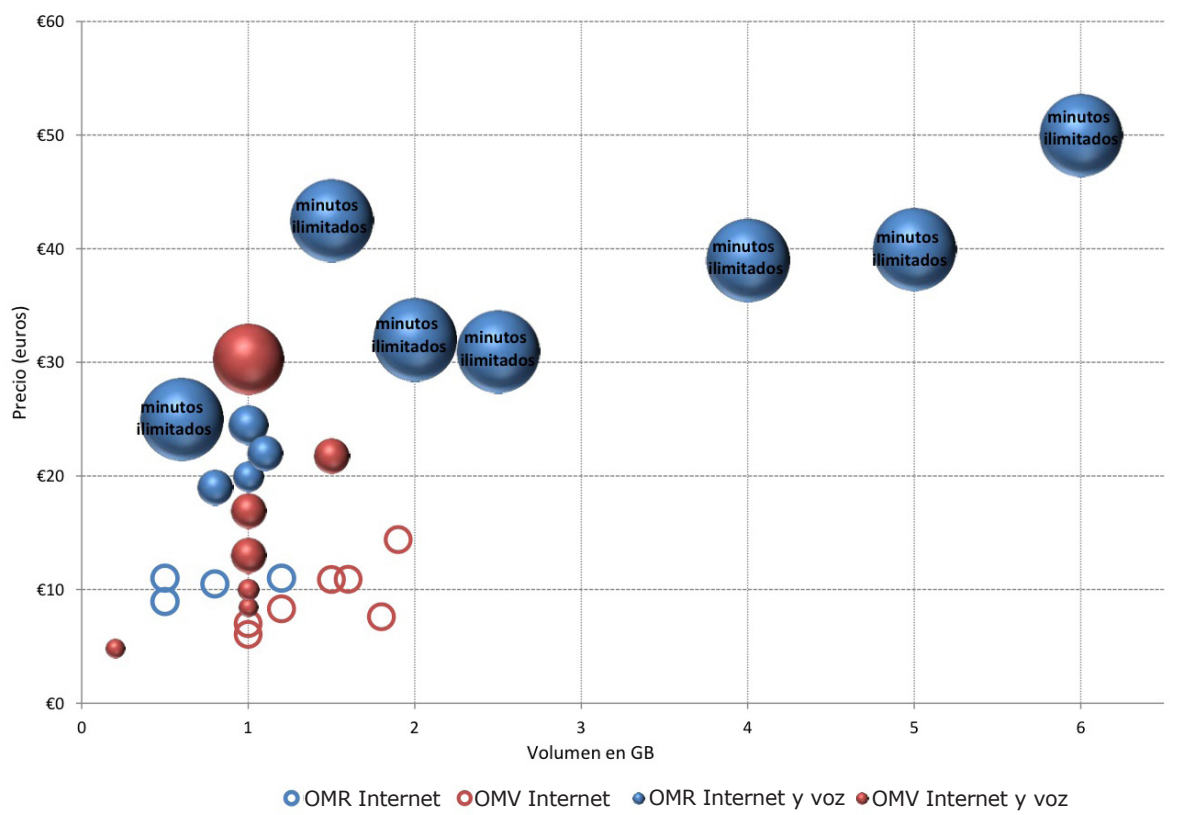

FUENTE: Elaboración propia. 


\section{GRÁFICO 13}

PRECIOS DE LAS OFERTAS PREPAGO DE BANDA ANCHA MÓVIL (Euros, IVA incluido, octubre 2014)

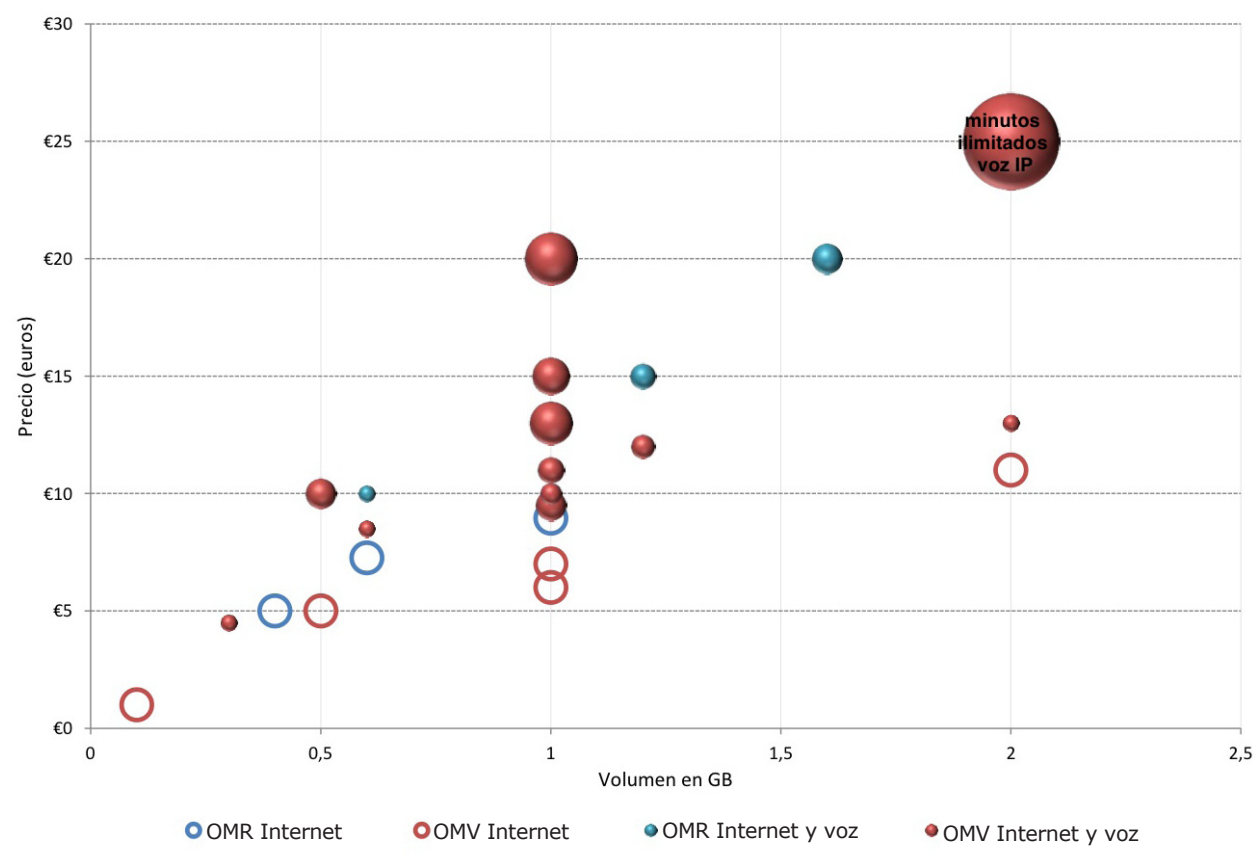

FUENTE: Elaboración propia.

La inspección de los gráficos revela una relación positiva entre el precio, el volumen de descarga y los minutos de llamadas. También se puede observar que los precios de las ofertas de postpago y de los OMRs son más altas (en un intervalo de 5 a 50 euros) que las de prepago y de los OMVs (en un intervalo entre 5 a 30 euros). Al mismo tiempo las ofertas de postpago y de los OMRs ofrecen mayor volumen de descarga de datos y más minutos de voz. Si por ejemplo nos concentramos en las ofertas de los OMRs y OMVs de un gigabyte de descarga (18 de las 54 ofertas), vemos que los OMVs tienen planes sensiblemente más baratos que los OMRs.

Los planes que sólo ofrecen banda ancha móvil (círculos) pueden complementarse con el servicio de voz si el cliente hace un pago adicional por minuto de llamada (en ciertos casos sólo se paga el establecimiento de llamada). Para las ofertas que no empaquetan la banda ancha con minutos de voz, se observa que cuanto mayor es el tráfico contratado menor es el precio que se paga por gigabyte (tarifas no lineales).

Finalmente, el Gráfico 14 muestra los precios mínimos mensuales de las ofertas exclusivas de banda ancha móvil. En el caso de que el operador no comercialice una oferta exclusiva de Internet mostramos con un asterisco la oferta más económica que 
incluya minutos de voz. Se han considerado tres intervalos de volumen de descarga: entre 0 y 0,99 GB (consumo bajo); entre 1 y 1,99 GB (consumo medio); y superior a 2 GB (consumo alto). A grandes rasgos, los precios de los OMVs son siempre inferiores a los de los OMRs. Sin embargo, Pepephone, MásMóvil y HappyMóvil no ofrecen planes con más de dos gigabytes. Por otro lado, muchas de las ofertas de los OMRs incluyen minutos de voz.

\section{GRÁFICO 14}

\section{PRECIOS MÍNIMOS (EUROS, IVA INCLUIDO) DE LAS OFERTAS DE BANDA ANCHA MÓVIL PARA SMARTPHONE EN ESPAÑA}

(Octubre 2014)

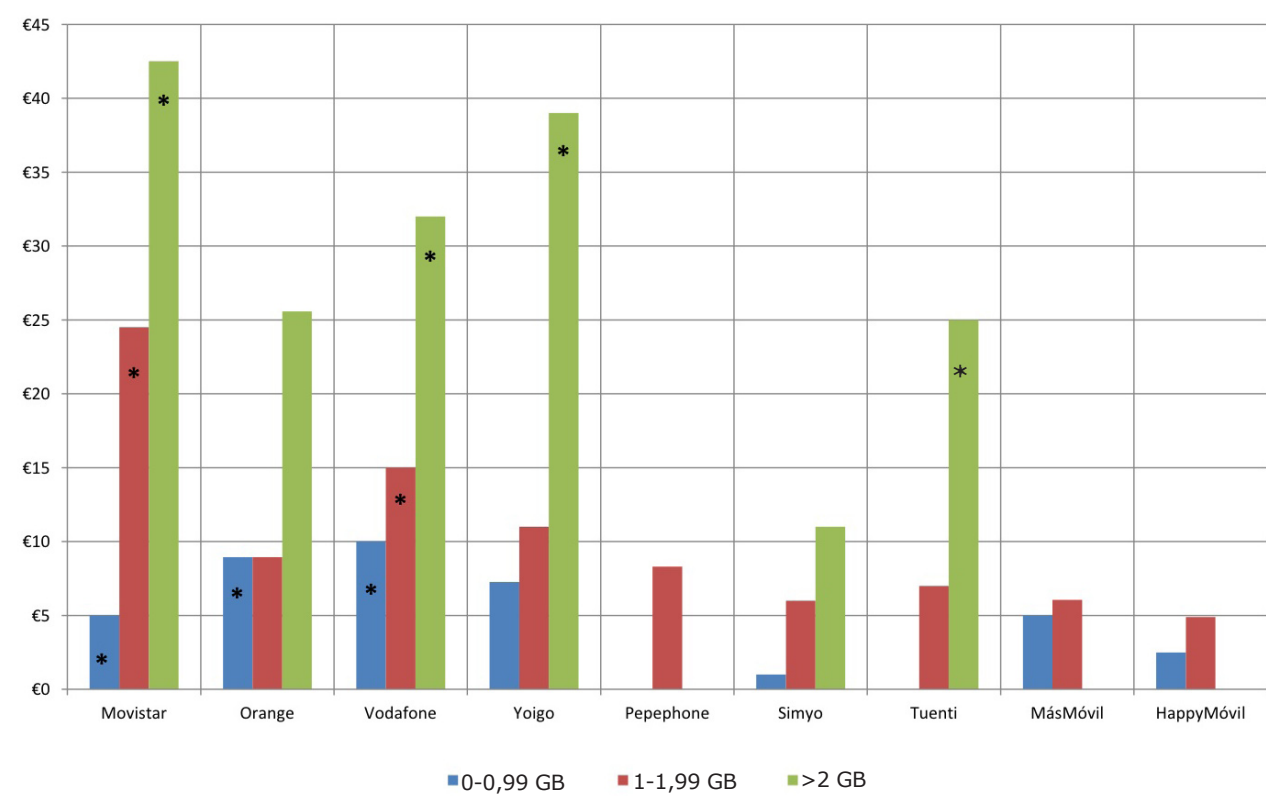

NOTAS: Pepephone y Tuenti usan la red de Movistar, y Simyo, MásMóvil y HappyMóvil la red de Orange. Planes de banda ancha y voz.

FUENTE: Elaboración propia.

\subsubsection{Comparativa de precios de las ofertas convergentes}

En último lugar, analizamos los precios de las ofertas convergentes usando una muestra de 23 planes recogidos en el tercer trimestre de 2014. El Gráfico 15 muestra los precios mínimos mensuales para los planes que integran en una sola factura los servicios de voz y banda ancha fija (incluyendo coste del alquiler de la línea con IVA) y los de voz y banda ancha móvil. Se vuelven a considerar los tres intervalos de descarga (bajo, medio, alto) del servicio de banda ancha móvil para segmentar las ofertas convergentes. Cuando el paquete más económico también incluye televisión 
se señala en el gráfico con un asterisco (Movistar ofrece televisión en todos su planes). En el gráfico aparecen operadores que tienen red fija y móvil, como son Movistar, Orange y Vodafone; y operadores con red fija que actúan como OMVs, como Jazztel (en negociaciones con Orange) y ONO (recientemente comprado por Vodafone). También incluimos a MásMóvil, que comercializa una oferta convergente gracias al acuerdo que mantiene con Jazztel en servicios fijos y con Orange en servicios móviles, y a Amena que es la marca «low cost» de Orange.

El análisis revela que Jazztel es uno de los operadores más económicos (en 2013 creció un 240 por 100 hasta llegar a superar el millón de clientes gracias a los paquetes de fijo-móvil). No obstante, las diferencias en precios son menores que las encontradas para ofertas de banda ancha móvil. Esto puede reflejar la competencia para captar nuevos clientes.

Según la CNMC, el análisis de las ofertas convergentes muestra diferencias de precios pequeñas, y en cualquier caso menores que las encontradas para las ofertas de banda ancha móvil. Esta situación puede reflejar la competencia entre operadores para captar clientes. En CNMC (2014b) se señala que en 2012 el precio medio de contratar separadamente los servicios fijos y móviles fue de 57,6 euros y en 2013 de

\section{GRÁFICO 15}

\section{PRECIOS MÍNIMOS (EUROS, IVA INCLUIDO) DE LAS OFERTAS CONVERGENTES EN ESPAÑA}

(Octubre 2014)

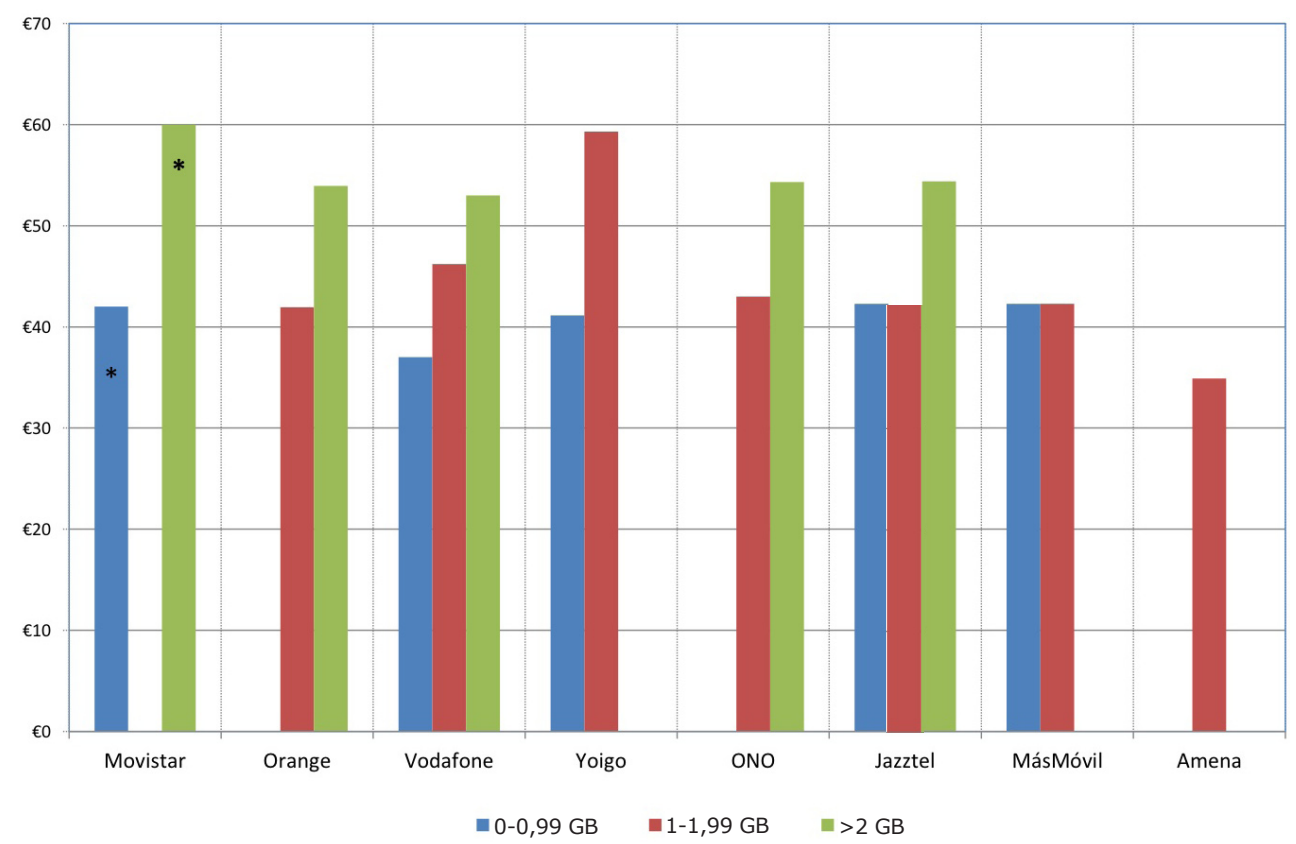

NOTAS: ONO usa la red de Movistar y Jazztel la de Orange para dar los servicios móvil.

FUENTE: Elaboración propia. 
49,3 euros al mes. En el caso de contratar un paquete convergente los consumidores podrían tener un ahorro promedio de alrededor de 6,5 euros.

\section{Conclusiones}

En este artículo hemos analizado la evolución y la situación actual del mercado de banda ancha móvil en España. Hemos destacado la importancia que ha tenido el progreso de los estándares tecnológicos europeos en el despliegue de la banda ancha móvil. Gracias a la innovación tecnológica, las velocidades de las tecnologías móviles se asimilan cada vez más a las de la banda ancha fija, y se han podido desarrollar aplicaciones para smartphones que están modificando los patrones de comunicación de la población y el uso que se da a los terminales móviles.

En los últimos años, la competencia entre los operadores móviles ha aumentado visiblemente. Los OMRs han tenido que acomodar la entrada de los OMVs, pero han creado segundas marcas que compiten directamente con ellos por los usuarios de bajo consumo. Esto ha producido rebajas significativas en los precios. Por otro lado, la convergencia entre las comunicaciones fijas y móviles también ha modificado las prácticas comerciales de los operadores, fomentando el lanzamiento de ofertas convergentes que han tenido mucho éxito entre los consumidores. Los OMRs buscan atraer y fidelizar a los consumidores ofreciendo una única oferta por todos los servicios de telecomunicaciones.

La intensificación de la competencia y el lanzamiento de las ofertas convergentes también han impulsado la reestructuración del mercado. Vodafone ha comprado ONO, Yoigo ha llegado a un acuerdo de compartición de infraestructuras con Movistar, y Orange está negociando la compra de Jazztel. En paralelo, los operadores de telefonía fija y de cable utilizan las redes de los OMRs para ofrecer servicios móviles y algunos han adquirido licencias de 4G. La reestructuración del mercado crea dudas sobre cuál será el papel de los OMVs en el futuro. Hasta ahora los OMVs han podido ofrecer servicios $3 \mathrm{G}$ utilizando las redes de los OMRs, pero en los próximos meses tendrán que negociar el uso de las nuevas redes de $4 \mathrm{G}$.

En España, en los últimos años se han producido bajadas significativas de precios y un fuerte crecimiento de la penetración de la banda ancha móvil, que es superior a la media de la UE. No cabe duda de que esta situación es fruto de la intensificación de la competencia, que se ha conseguido gracias a la actividad reguladora de las autoridades españolas y comunitarias y al aumento en el número de operadores. La regulación de los precios de terminación ha reducido los precios de las llamadas offnet y ha incentivado la aparición de ofertas empaquetadas. Por otro lado, la entrada de los OMVs ofrece a los consumidores un gran abanico de ofertas comerciales. A pesar de esto, España se sitúa aún por debajo de la media de la UE en penetración de tarjetas SIM activas y es uno de los países con precios más elevados para servicios móviles. El principal reto para el futuro será mantener la competencia en un mercado que tiende a la concentración. 


\section{Referencias bibliográficas}

[1] ADAMS, W.y J. YELLEN (1976): «Commodity bundling and the burden of monopoly», Quarterly Journal of Economics, 90, 475-98.

[2] BEKKERS, R. (2001): Mobile telecommunications standards: GSM, UMTS, TETRA and ERMES, Artech House, Boston.

[3] BEL, G, J. CALZADA y X.FAGEDA (2006): «Liberalización y competencia en España: ¿dónde estamos?», Información Comercial Española, vol. 829, 123-144.

[4] CABRAL, L. y D. SALANT (2013): «Evolving technologies and standards regulation», International Journal of Industrial Organization,

[5] CALZADA, J. y A. ESTRUCH (2011): «Telefonía móvil en España: regulación y resultados», Cuadernos Económicos del ICE, 81, 39-71.

[6] CALZADA, J. y A. ESTRUCH (2013): «Comunicaciones móviles en la Unión Europea: Tecnología, Políticas y Mercado», Papeles de Economía Española, 136, 29-49.

[7] CALZADA, J. y F. MARTÍNEZ SANTOS (2014): «Broadband prices in the European Union: Competition and commercial strategies», Information Economics and Policy, 7, 24-38.

[8] CMT (2013a): Informe Económico Sectorial 2012. Comisión del Mercado de las Telecomunicaciones.

[9] CMT (2013b): «Estrategias de venta de terminales y precio de los servicios móviles», Nota ocasional 7, Comisión del Mercado de las Telecomunicaciones.

[10] CNMC (2014a): «Efecto arrastre entre las demandas de servicios fijos y de servicios móviles tras la eclosión en España de los paquetes convergentes de servicios fijos y móviles», Documento de Trabajo número 2, abril 2014.

[11] CNMC (2014b): «Cambios de operadores de los servicios de comunicaciones electrónicas en el sector residencial en 2013», Documento de Trabajo número 3, julio 2014.

[12] CNMC (2014c): «Informe de seguimiento de las ofertas comerciales de servicios de comunicaciones móviles entre 2012 y 2013», Documento de Trabajo número 12, julio 2014.

[13] CNMC (2014d): Informe Económico de las Telecomunicaciones y del Sector Audiovisual 2014, Comisión Nacional de los Mercados y de la Competencia.

[14] COMISIÓN EUROPEA (2012a): Digital Agenda for Europe, Scoreboard 2012. Directorate-General for Communication Networks, Content and Technology (CONNECT), Bruselas.

[15] COMISIÓN EUROPEA (2012b): E-communications Households Survey. Report. Special Eurobarometer 381. Directorate-General for Informatio Society and Media, Bruselas.

[16] COMISIÓN EUROPEA (2013): «The mobile use of the Internet by individuals and enterprises», Digital Agenda Scoreboard 2013, chapter 4, june 2013

[17] CRANDALL, R., W. LEHR y R. LITAN (2007): «The Effects of Broadband Deployment on Output and Employment: A Cross-sectional Analysis of U.S. Data», Issues in Economic Policy, The Brookings Institution, No. 6, July.

[18] CZERNICH,N,O.FALCK,T.KRETSCHMER y L. WOESSMANN (2011), «Broadband Infrastructure and Economic Growth», Economic Journal, Royal Economic Society, vol. 121(552), 505-532.

[19] EVANS, D. y M. SALINGER (2005): «Why do firms bundle and tie? Evidence from 
competitive markets and implications for tying law», Yale Journal on Regulation, 22, 37-89.

[20] GANDAL, N., D. SALANT y L. WAVERMAN (2003): «Standards in Wireless Telephone Networks», Telecommunications Policy, 27, 325-332.

[21] GRUBER, H. y VALLETTI, T. (2003): «Mobile telecommunications and regulatory frameworks», en Emerging telecommunications networks: the international handbook of telecommunications economics, volume II, Editor(s): Madden, Cheltenham, Edward Elgar.

[22] GRUBER, H. y F. VERBOVEN (2001): «The Difusion of Mobile Telecommunication Services in the European Union», European Economic Review, 45, 577-588.

[23] GRUBER, H. (2007): «3G mobile telecommunications licenses in Europe: a critical review», Info, vol. 9, n.6, 2007, p. 35-44.

[24] GRZYBOWSKI, L. (2005): «Regulation of mobile telephony across the European Union: an empirical analysis», Journal of Regulatory Economics, 28 (1): 47-67.

[25] GRZYBOWSKI, L. (2008): «The impact of regulation on the retail prices in fixed-line telephony across the European Union», Telecommunications Policy, 32 (2): 131-144.

[26] GRZYBOWSKI, L. (2012): Fixed-to-Mobile Substitution in the European Union, mimeo.

[27] HILLEBRAND, F. (2013): «The Creation of Standards for Global Mobile Communication: GSM and UMTS Standardization from 1982 to 2000», IEEE Wireless Communications, 24-33.

[28] HILLEBRAND, F. (2013): «The creation of standards for global mobile communication: GSM and UMTS standardization from 1982 to 2000», Wireless Communications, IEEE, Volume 20 (5), 24-33.

[29] KOSKI, H. y T. KRETSCHMER (2004): «Entry, Standards and Competition: firm strategies in the diffusion of mobile telephony», Review of Industrial Organization, 26, p. 89-113.

[30] McAFEE, R., J. McMILLAN y M. WHINSTON (1989): «Multiproduct monopoly, commodity bundling and correlation of values», Quarterly Journal of Economics, 104, 371-84.

[31] NALEBUFF, B.(2004): «Bundling as an entry barrier», Quarterly Journal of Economics, $119,159-87$.

[32] OFCOM (2014): «The European Broadband Scorecard», Research Document, 12 March 2014.

[33] OCDE (2011): OCDE Communications Outlook 2011. OCDE Publishing.

[34] OCDE (2013): OCDE Communications Outlook 2013. OCDE Publishing.

[35] PRAT, A. y VALLETI, T. (2003): «Spectrum Auctions Versus Beauty Contests: Costs and Benefits», en Mario Baldassarri y Luca Lambertini (eds.), Antitrust, Regulation and Competition, Palgrave Macmillan, Londres.

[36] SUNG, N. y M. KWON (2011): «An empirical analysis of the state of competition in OECD mobile wireless markets», 22nd European Regional Conference of the International Telecommunications Society (ITS2011), Budapest.

[37] VOGELSANG, I. (2010): «The Relationship between mobile and fixed-line communications: a survey», Information Economics and Policy, 22(1): 4-17. 